\title{
Phosphatidylinositol-3-kinase activity during in vitro dendritic cell generation determines suppressive or stimulatory capacity
}

\author{
Valentina Di Caro • Antonella D'Anneo • \\ Brett Phillips · Carl Engman · Jo Harnaha • \\ Massimo Trucco $\cdot$ Nick Giannoukakis
}

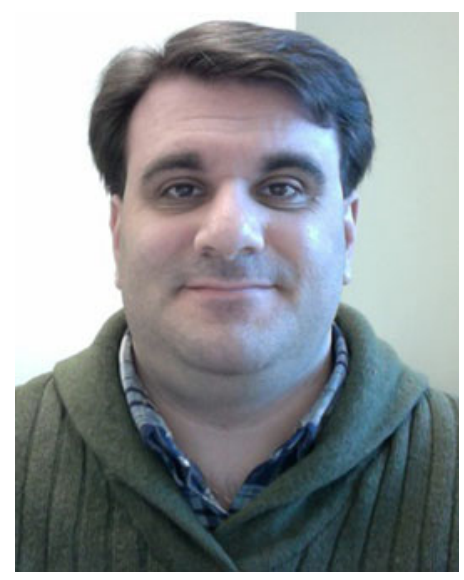

Published online: 8 April 2011

Nick Giannoukakis

(C) Springer Science+Business Media, LLC 2011

\begin{abstract}
Modulating PI3K at different stages of dendritic cells (DC) generation could be a novel means to balance the generation of immunosuppressive versus immunostimulatory DC. We show that PI3K inhibition during mouse DC generation in vitro results in cells that are potently immunosuppressive and characteristic of CD8alpha- CD11c $+\mathrm{CD} 11 \mathrm{~b}+$ DC. These DC exhibited low surface class I and class II MHC, CD40, and CD86 and did not produce TNF-alpha. In allogeneic MLR, these DC were suppressive. Although in these mixed cultures, there was no increase in the frequency of CD4+ CD25+ Foxp3+ cells, the Foxp3 content on a per cell basis was significantly increased. Sustained TLR9 signaling in the presence of PI3K inhibition during DC generation overrode the cells' suppressive phenotype.
\end{abstract}

Keywords Dendritic cells · Phosphatidylinositol-3-kinase · Immunoregulation · TLR · Oligonucleotides · Signaling

V. Di Caro · A. D’Anneo · B. Phillips · C. Engman .

J. Harnaha $\cdot$ M. Trucco $\cdot$ N. Giannoukakis

Department of Pediatrics, Division of Immunogenetics,

Children's Hospital of Pittsburgh, University of Pittsburgh

School of Medicine, 4401 Penn Avenue, Pittsburgh,

PA 15224, USA

V. Di Caro

RiMed Foundation, Piazza Sett' Angeli 10,

90134 Palermo, Italy

\section{A. D'Anneo}

Department of Biochemical Sciences, University of Palermo, via del Vespro 129, 90127 Palermo,

Sicily, Italy

\section{N. Giannoukakis}

Department of Pathology, University

of Pittsburgh School of Medicine, Children's Hospital

of Pittsburgh, 4401 Penn Avenue, Pittsburgh,

PA 15224, USA

N. Giannoukakis $(\bowtie)$

Department of Pathology, University of Pittsburgh

School of Medicine, Children's Hospital

of Pittsburgh, Rangos Research Center

Lawrenceville 6123, 530 45th Street,

Pittsburgh, PA 15201, USA

e-mail: ngiann1@pitt.edu

\section{Introduction}

Many studies indicate that the PI3K pathway is an important point of regulation of immune cell activation and function in innate immunity [1-3]. While most reports indicate that the PI3K pathway is instrumental in cell survival, prevention of apoptosis, proliferation, B- and T-cell receptor signaling as well as chemotaxis in many immune cells, this signaling pathway can also control the production, accumulation, and binding of transcription factors required for the expression of critical proinflammatory cytokines like IL-12 and immunosuppressive cytokines like IL-10 [4-8]. Once activated, PI3K signals mainly via Akt with multiple downstream targets that include the mammalian target of rapamycin (mTOR), glycogen synthase kinase- 3 beta (GSK-3 beta), and forkhead box O (FoxO) transcription factors [3, 9-11]. PI3K is also important in the control of DC maturation and survival [3, 9-12]. A number of studies demonstrate that PI3K is important in the development and differentiation of human DC in vitro $[4,7,11,13-16]$ even though its precise role at discrete points during DC development is unclear.

The role of PI3K in innate immunity has raised questions about its importance in acting as a safety mechanism 
in controlling the strength of immune responses to pathogens [17]. Modulating its activity could affect the phenotype of innate immune cells in vivo as well as during their in vitro generation from progenitors. PI3K modulation in dendritic cells (DC) for example could determine a balance in whether they adopt an immunostimulatory or an immunosuppressive state. In DC, PI3K is activated by LPS, peptidoglycan, CD40 ligand, RANK ligand, and CpG oligonucleotides, all which result in DC production of IL-12 [17]. Also, PI3K is activated following stimulation of many of the characterised toll-like receptors (TLRs) [17]. While most of the TLR signals in DC are proinflammatory, some studies indicate that TLR9 can act, under certain circumstances, to induce immunosuppressive activity in DC [17]. TLR9 activates p38 MAP Kinase (p38) which is one of the main pathways culminating in nuclear translocation and activity of NF-kappaB in DC [3, 8, 18-20]. However, TLR9 can also signal through PI3K [3, 8, 18-20]. Indeed, PI3K can regulate p38 [1-3, 8-11, 15-22], and such a mechanism could underlie TLR9 effects on the maintenance or shift of DC activity toward immunosuppression.

Dendritic cells are the body's sentinels largely responsible for host surveillance against microenvironmental anomalies including pathogen invasion, infection, and damaged tissue architecture, while coordinating the mechanisms of self-tolerance [23-26]. They have become very attractive candidates, in recent years, for tumor and antiviral immunotherapy [27-30]. Depending on the methods used to generate DC from monocyte progenitors present in human PBMC, or bone marrow progenitors from mice, the outcome can be a population of cells that potently activate the immune system against pathogens and tumors, or cells that can induce antigen-specific immune hyporesponsiveness and even tolerance [31,32]. Many lines of investigation show that DC in a functionally immature state (characterised by low to absent co-stimulatory molecules) are powerful agents of immune hyporesponsiveness [25, 33]. Exogenous administration of functionally immature DC achieves long-term and stable allograft survival in a variety of mouse and rat models and prevents a number of autoimmune diseases [34-38]. Mechanistically, functionally immature DC act by inducing anergy either via direct cell contact and/or altering cytokine production inside the lymphoid organs [33, 39, 40]. Furthermore, as described more recently, DC rendered tolerogenic can directly upregulate the number and function of regulatory immune cell subsets, especially antigen-specific CD4+ CD25+ Foxp3+ T-cells as well as a class of CD8+ immunosuppressive T-cells [41-49]. Some studies additionally suggest that tolerogenic DC could also act by degrading tryptophan in the local environment, following the upregulation of the key metabolising enzyme IDO [50-52].

The generation of DC for immunotherapy in rodent models or humans mostly relies on the inclusion of
GM-CSF and IL-4 in the culture medium [53-62]. Very little is known about the molecular pathways active in DC during this culture period that could potentially be exploitable to shift the developmental balance in favor of an immunostimulatory or immunosuppressive DC product.

We have begun an investigation into the intracellular pathways active and altered during the generation of DC in vitro. As a first approach, we focused on the signaling in mouse DC developing from bone marrow progenitors. We have discovered that the PI3K pathway can be an important regulator in determining whether GM-CSF/IL-4-cultured DC progenitors differentiate into DC with immunosuppressive or immunostimulatory capacity. Furthermore, we have also demonstrated that TLR9 signaling during the generation of PI3K-impaired DC overrides their suppressive capacity. Interestingly, we also discovered that initiation of PI3K inhibition after DC generation in vitro cannot confer an immunosuppressive capacity to DC and that TLR9 signaling potentiates the stimulatory phenotype of DC rendered PI3Kimpaired post-generation in vitro. Our data suggest that PI3K inhibition during the generation period yields immunosuppressive DC resembling CD8alpha- CD11c+ CD11b+ cells while $\mathrm{PI} 3 \mathrm{~K}$ inhibition post-generation promotes immunostimulatory DC whose activity is potentiated by TLR 9 signaling. At the signaling level, we uncovered a dynamic and complex interplay between the phosphorylation of $\mathrm{p} 38$ and GSK-3 beta during DC generation in vitro.

\section{Materials and methods}

\section{Biochemicals}

The PI3K inhibitor LY-294002 was purchased from Calbiochem (EMD Chemicals, Gibbstown, NJ) as an ultrapure powder and reconstituted in DMSO and reconstituted for use in cell culture in endotoxin-free sterile PBS. Cell culture reagents (media and sera) were all purchased from Invitrogen (Carlsbad, CA). CpG oligonucleotide ODN 1826 [63-66] was synthesised to high purity with undetectable levels of endotoxin by IDT technologies (San Diego, CA). All other biochemicals and reagents were purchased from Sigma, BioRad or Invitrogen unless otherwise indicated.

Animals

C57BL/6 and Balb/c mice were purchased from Jackson Laboratories (Bar Harbor, ME). All animals were kept under specific pathogen-free conditions. Bone marrow and spleen were collected from 8- to 10-week-old mice. Animal care and all procedures were performed in accordance with institutional (University of Pittsburgh DLAR and IACUC), state and federal guidelines. 
Generation of dendritic cells

Dendritic cells were generated from bone marrow progenitors obtained from C57BL/6 mice in 6-day cultures with GM-CSF and IL-4 using previously published protocols $[67,68]$ in the continuous presence or absence of LY294002 (25 micromolar final concentration) and/or CpG ODN 1826 (0.5 micromolar final concentration). DC generated in cultures with only GM-CSF and IL-4 served as controls. Parallel DC were generated for 6 days in the presence of GM-CSF and IL-4 alone, GM-CSF/IL-4 and LY-294002, GM-CSF/IL-4 and ODN 1826, or GM-CSF/ IL-4 and LY-294002/ODN 1826. Culture supernatants and cells were collected on day seven for all further studies. In some experiments, the PI3K inhibitor LY-294002 with or without ODN 1826 was added in GM-CSF/IL-4-generated $\mathrm{DC}$ at the end of the 6-day culture period (after the GMCSF/IL-4 DC generation period). Supernatants and cells from these cultures were collected $24 \mathrm{~h}$ after the addition of the PI3K inhibitor/ODN 1826.

Phosphoprotein determination, Western blotting, and data analysis

Whole, cytoplasmic, and nuclear protein extracts from DC collected at the times illustrated above were obtained using NER-PER or M-PER protein extraction reagents as appropriate (Pierce Biotechnology). Protein concentration was determined by the BCA Protein Assay Kit (Pierce) and standardised to bovine serum albumin. Nuclear $(10 \mu \mathrm{g})$, cytoplasmic $(10 \mu \mathrm{g})$ or whole protein lysates $(40-60 \mu \mathrm{g})$ from the DC were separated in 10\% SDS-PAGE, electrotransferred onto a PVDF membrane (BioRad) and incubated with specific antibodies to the indicated intracellular signaling molecules (p38 MAP Kinase, Akt, NF-kappaB p65, GSK-3beta as well as their signaling-related phosphospecific antibodies (NFkB p65 (C20) sc-372 Santa Cruz Biotechnology; Akt, 9272, Cell Signaling; p-Akt (Ser 473) 9271, Cell Signaling; GSK-3 $\beta$ (11B9) sc-81462, Santa Cruz Biotechnology; p-GSK-3 $\beta$ (Ser 9) 9336, Cell Signaling; p38 MAP Kinase (N20) sc-728, Santa Cruz Biotechnology; p-p38 MAP Kinase (Tyr 182) sc-7975-R, Santa Cruz Biotechnology; ERK (K23) sc-94, Santa Cruz Biotechnology; $\beta$-actin, 5441, Sigma) followed by incubation with horseradish peroxidase (HRP)-conjugated secondary antibody (HRP-conjugated Rabbit anti Goat IgG, 305-035-003, Jackson ImmunoResearch Labs; HRPconjugated Goat anti Rabbit IgG, 111-035-047, Jackson ImmunoResearch Labs; HRP-conjugated Goat anti Mouse IgG, 31430, Pierce). Protein-antibody complexes were visualised by enhanced chemiluminescence with the GE Healthcare ECL system.
Immune cell isolation, allogeneic mixed leukocyte reaction (MLR), fluorescence-activated cell sorting (FACS), flow cytometry, and cytokine detection/ measurement

T-cells were prepared from freshly isolated splenocytes of C57BL/6 mice. CD4+ or CD4+ CD25+ T-cells were purified using the CD4+ T-cell isolation columns ( $\&$ D Systems) or a specific CD4+ CD25+ isolation kit as per the manufacturer's recommendations (Miltenyi Biotec). These cells were maintained in RPMI 1640 medium supplemented with $10 \%$ fetal bovine serum, 50 micromolar beta mercaptoethanol, $1 \%$ sodium pyruvate, and $1 \%$ nonessential amino acids (all purchased from Invitrogen).

For MLR to determine the capacity of the DC for allostimulation in vitro, $2 \times 10^{5} \mathrm{CD} 4+$ T-cells from allogeneic Balb/c mice were co-cultured with an equal number of irradiated DC from bone marrow progenitors of C57BL/6 mice (DC generated from cultures as described earlier) for a period of 5 days in RPMI with 10\% FBS. At the end of incubation, 10 micromolar BrdU was added for the final $16 \mathrm{~h}$ to assess proliferation. T-cell proliferation was determined by the level of FITC fluorescence and \% cells fluorescent by FACS analysis using the FITC-BrdU flow cytometry kit (BD Pharmingen).

The frequency of CD4+ CD25+ Foxp3 \pm cells in the MLR co-cultures was measured by fluorescence-activated cell sorting analysis (FACS) following the 6-day DC generation period or the time after the addition of the PI3K inhibitor/ODN 1826 in differentiated DC. Cells were removed from the plastic multiwell plates and stained with antibodies specific for CD4, CD25, and Foxp3 (CD4, clone GK1.5, BD Biosciences; CD25, clone 7D4, BD Biosciences; Foxp3, clone FJK-16s, eBiosciences). The fluorophores on the antibodies were complementary with distinct emission spectra so that no bleeding or overlap would occur during FACS analysis. Antibody-specific isotypes were used throughout to exclude non-specific staining.

Luminex-based multianalyte assays using commercially purchased systems (Beadlyte Assay System, Upstate Biotechnology) were performed on culture supernatants (DC alone, or MLR supernatants) to profile cytokine productions and levels of each cytokine. All measurements were performed in duplicate from triplicate DC cultures on at least two occasions.

\section{Statistical analyses}

ANOVA and the Student's $t$ test in Graph Pad Prism version 4.0 were used to determine statistical significance in the measurements among the different DC treatment groups and the biologic responses in the presence or absence of the PI3K inhibitor with or without ODN 1826. 
A $P$ value of less than 0.01 among the means was considered statistically relevant.

\section{Results}

DC generated in the presence of a PI3K inhibitor exhibit a morphologically immature phenotype with decreased CD11c expression

It is well known that immature DC are metastable cells that can be manipulated toward immunosuppressive or immunostimulatory capacity in vitro $[25,31,69,70]$. The signaling pathways inside their hematopoietic progenitors and how they change during DC generation in vitro are not completely known, although data are emerging demonstrating an important role of the PI3K pathway [11, 71-74]. A number of studies indicate that PI3K could be modulated during DC generation and that, depending on its activity, the balance in favor of generating immunosuppressive or immunostimulatory DC could be altered [3-5, 9, 11, 12, 14, 17, 21, 73, 75].

To determine the effects of PI3K inhibition during the generation of DC from bone marrow progenitors on the morphological maturity of the DC, we stained day 6 DC (control and those generated in the presence of
LY-294002) with DAPI and a FITC-conjugated CD11c antibody. In Fig. 1, we show that control DC are larger in diameter and suggestive of a larger volume compared to PI3K-impaired DC. The density of CD11c on the PI3Kimpaired DC was considerably less than that on control DC. Overall, the morphology of the DC generated in the presence of LY-294002 was reminiscent of immature DC [59, 76, 77].

PI3K inhibition can affect cell viability. We determined whether PI3K inhibition, using the specific pharmacologic inhibitor LY-294002 [16, 74, 78-80] during the process of murine DC generation from GM-CSF/IL-4-cultured bone marrow progenitors, induced apoptotic and/or necrotic events in the differentiating cells in vitro. We measured viability and apoptosis onset in control or LY-294002supplemented GM-CSF/IL-4 DC cultures by propidium iodide (PI) and Annexin V staining at the end of 6-day cultures (standard protocol for generating murine DC in vitro; [59]). In Fig. 1, we show that less than $10 \%$ of the total cells in culture at day 6 are PI- and Annexin V-co-positive (graph and representative FACS plots). Furthermore, there are no differences in PI staining or Annexin V staining between control and LY-294002-treated DC. Routinely, by day 6 , we obtain about $2 \times 10^{6}$ CD11c+ DC from $3 \times 10^{7}$ bone marrow progenitors $[59,76,77]$. We did not observe any significant differences

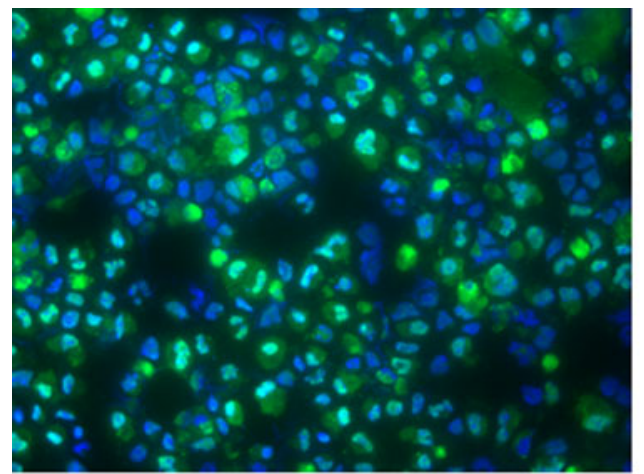

Control DC

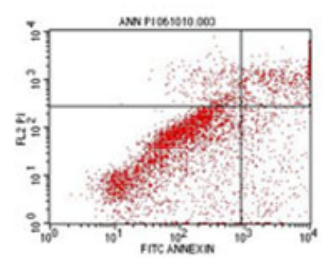

Fig. 1 LY-294002-generated DC exhibit a morphologically immature phenotype in vitro. DC generated in GM-CSF/IL-4 cultures in the presence or absence of LY-294002 were stained with a FITC-labeled anti-CD11c antibody and then counterstained with DAPI. The panels represent fluorescence of CD11c+ cells (green) and the DAPI-stained nuclei (blue) in cytospins. We show cells at $\times 40$ magnification. The low levels of FITC in the LY-294002-generated DC indicate an immature state. The FACS quadrants below the immunofluorescence

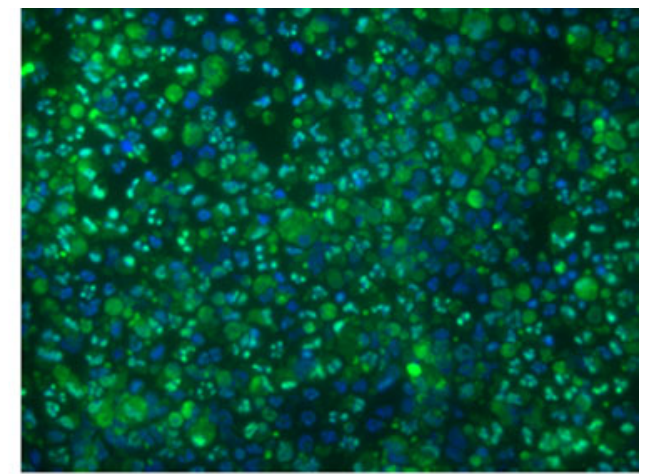

LY-294002-generated DC
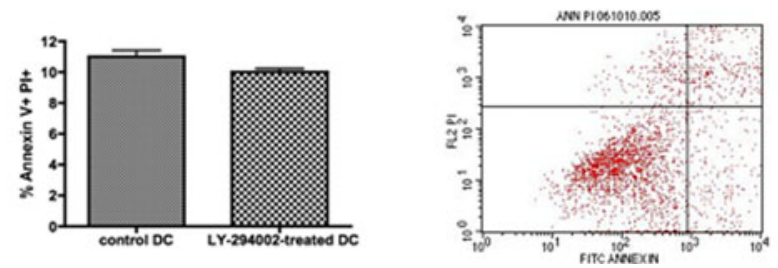

images are representative of the accumulation of propidium iodide (PI; $y$-axis) and Annexin V staining ( $x$-axis) of day 6 DC (control and LY-294002-generated). The graph summarises the degree of apoptotic/necrotic cells with the bars indicating the means of triplicate cultures and the error bars the SEM. There were no significant differences in apoptotic/necrotic cells under control or LY-294002 conditions 
in the yield of CD11c+ DC when LY-294002 was included in the cultures (data not shown).

PI3K inhibition during the generation of DC from murine bone marrow progenitors confers immunosuppressive capacity in allogeneic MLR in vitro

Based on the morphology of the LY-294002-generated DC in vitro, we proposed that the immature phenotype could extend to their functional capacity in affecting alloresponses in vitro. To directly test this possibility, we established standard 5-day MLR co-cultures with irradiated control DC or LY-294002-generated DC and an equal number of splenic T-cells from allogeneic mice $\left(2 \times 10^{5}\right.$ DC: $2 \times 10^{5}$ T-cells). At the end of the MLR, we collected the supernatants of the multiwell plates and measured proliferation of cells using flow cytometry-based ascertainment of BrdU incorporation as described in the "Materials and methods" section. In Fig. 2, we show that LY-294002-generated DC were unable to stimulate the proliferation of allogeneic T-cells beyond the basal proliferation seen in wells with the T-cells alone.

DC generated in the presence of a PI3K inhibitor exhibit features similar to immunoregulatory CD8alpha- CD11c+ CD11b+ DC along with decreased cell surface CD40 and CD86 co-stimulatory proteins

Using LY-294002-generated DC in MLR, the proliferation of allogeneic T-cells was impaired and suggested a number of possible mechanisms including: (1) low levels of MHC on the DC surface; (2) poor provision of costimulation by the PI3K-impaired DC; (3) production of immunosuppressive cytokines by the DC or by the T-cells in the MLR co-cultures; (4) a shift in the phenotype of the responsive T-cells (TH1 to TH2); or (5) the activation/proliferation of adaptive Foxp3+ Tregs in the MLR that could suppress the proliferation of non-regulatory T-cells. To determine which of these mechanisms could underlie the hyporesponsiveness conferred by the LY-294002-generated DC, we first measured the levels of class I (H-2d and H-2K) and class II (I-Ab) molecules on the surface of CD11c $+\mathrm{CD} 11 \mathrm{~b}+$ cells. DC generated in the presence of LY-294002 clearly exhibited significant decreases in class I and II MHC (bottom panels in Fig. 3a) in CD11c+ CD11b+ and CD11c+ $\mathrm{CD} 11 \mathrm{~b}-$ cells. Interestingly, the distribution of CD11c and CD11b changed significantly in pattern in LY-294002generated DC (top panels in Fig. 3a). By FACS analysis, control-generated DC segregated into four distinguishable populations along the lines of CD11c and CD11b (top left panel, Fig. 3a), whereas LY-294002-generated DC segregated

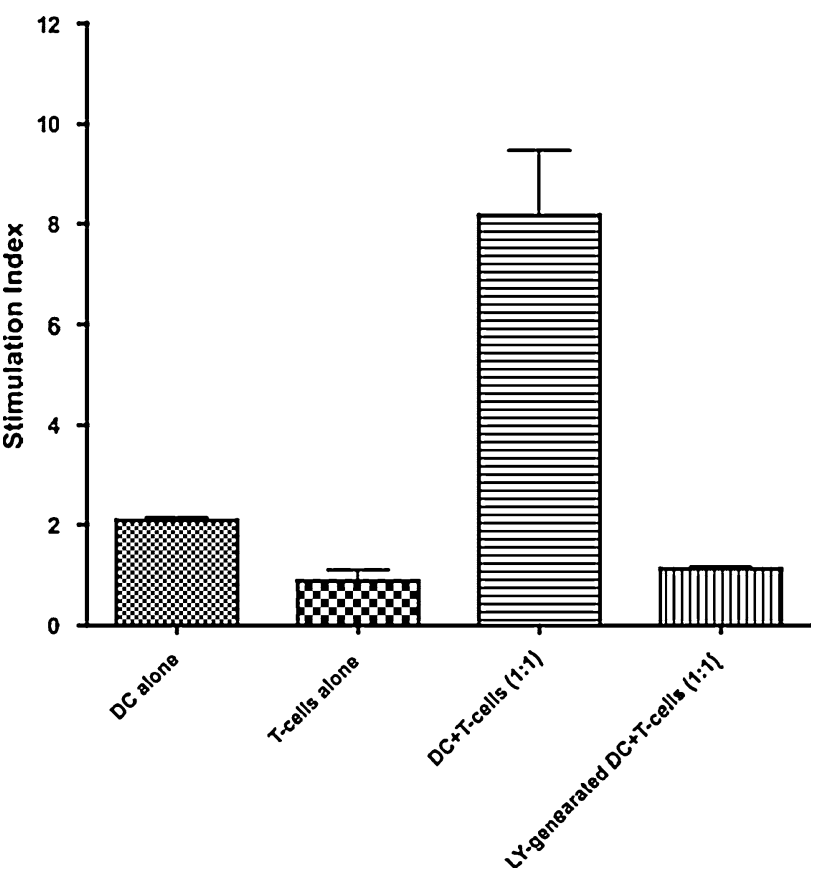

Fig. 2 LY-294002-generated DC suppress allostimulation of T-cells in mixed leukocyte culture in vitro. Irradiated control or LY-294002generated DC were co-cultured at an equal ratio of DC:T-cells for 5 days. The T-cells were enriched from the spleen of an allogeneic mouse strain. At the end of the incubation, the supernatants were collected, and the cells were further cultured in the presence of BrdU. After an overnight incubation in BrdU, the cells were collected and processed to measure the frequency of BrdU+ cells (representing proliferating cell frequency) by FACS. The graph shows the frequency of proliferating cells as a stimulation index $(S I)$. The SI was calculated by dividing the proliferation of T-cells in the different co-cultures (or the DC alone) by background proliferation. Proliferation observed in cultures of T-cells only was considered to be the background level and assigned a value of 1 . The error bars represent the SEM of quadruplicate wells. $P<0.0001$ by Student's $t$ test comparing proliferation of allogeneic T-cells in co-culture with control-generated DC compared to LY-294002-generated DC

into two readily distinguishable populations, the majority of cells exhibiting a CD $11 \mathrm{c}^{+/ \mathrm{HIGH}} \mathrm{CD} 11 \mathrm{~b}^{\text {INTERMEDIATE }}$ surface phenotype (top right panel, Fig. 3a).

We then measured the frequency of CD86+, CD80+, and CD40+ DC as well as the relative cell surface expression of these three important co-stimulatory proteins by flow cytometry. In Fig. 3b, we show that generation of murine bone marrow DC in the presence of LY-294002 results in significant suppression of CD40 and CD86 on the cell surface of the DC compared to that on control DC during the generation period, in vitro (determined as mean fluorescence intensity of the cell surface protein by FACS analysis). In the same figure (right-side panel), we show that the frequency of CD86+ and CD40+ DC in cultures generated in the presence of LY-294002 is significantly lower than in cultures of control DC. These data suggest 
A
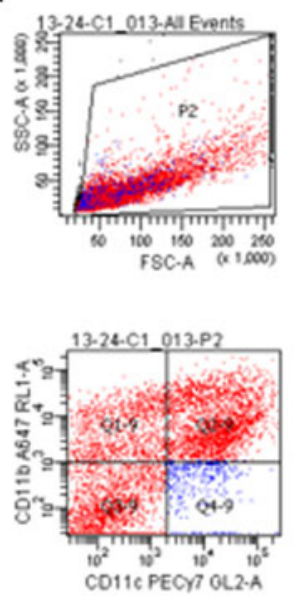

H-2D MFI

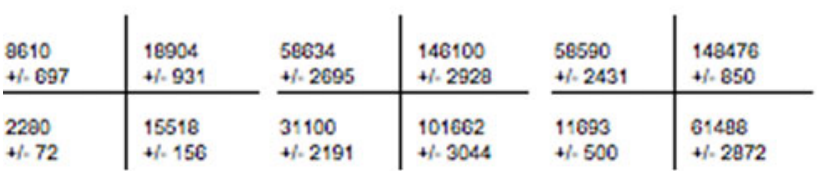

Control-generated DC

$\%$ of parent population

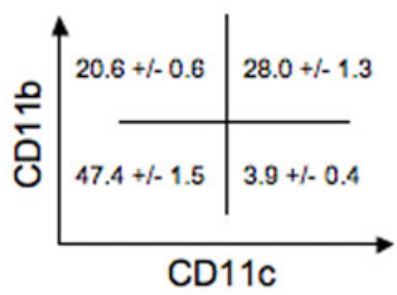

LY-294002-generated DC
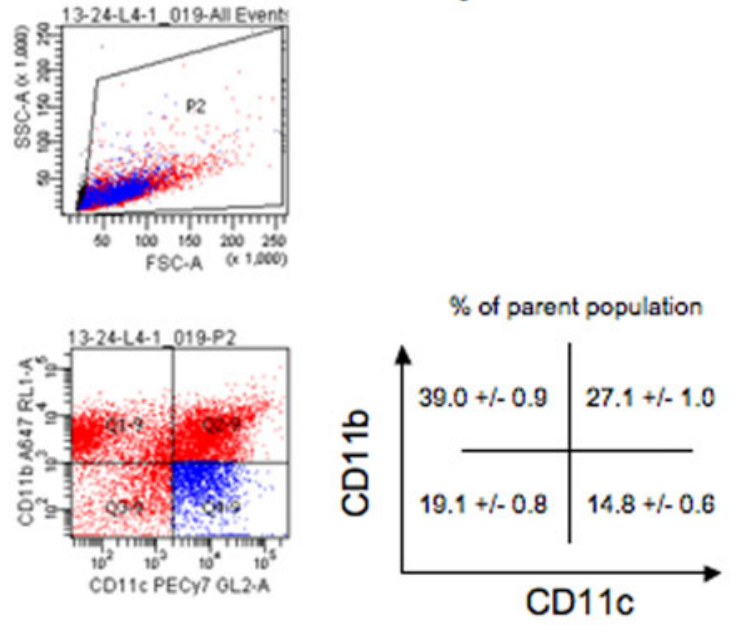

H-2D MFI

$\mathrm{H}-2 \mathrm{~K} \mathrm{MFI}$

I-Ab MFI
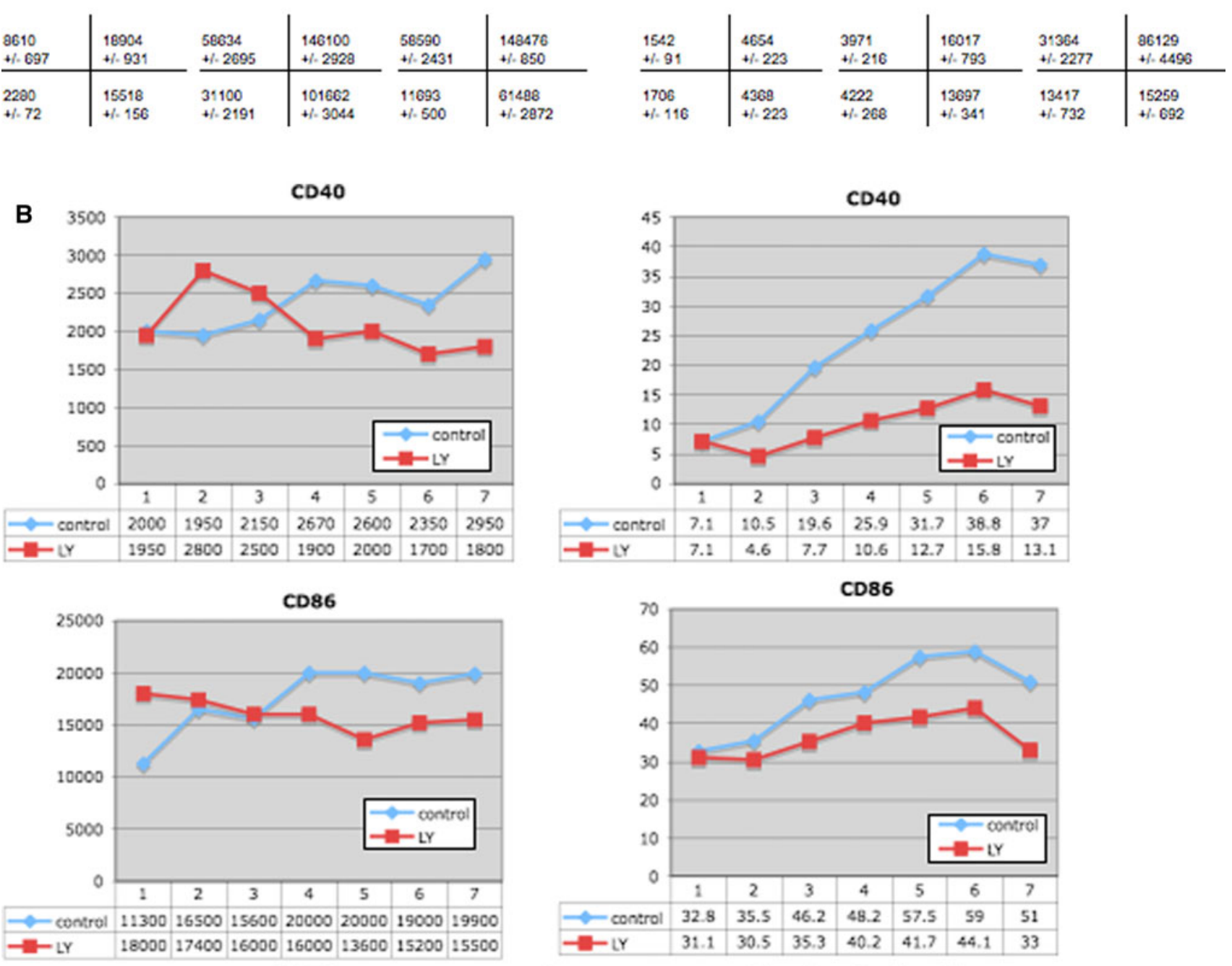

MFI

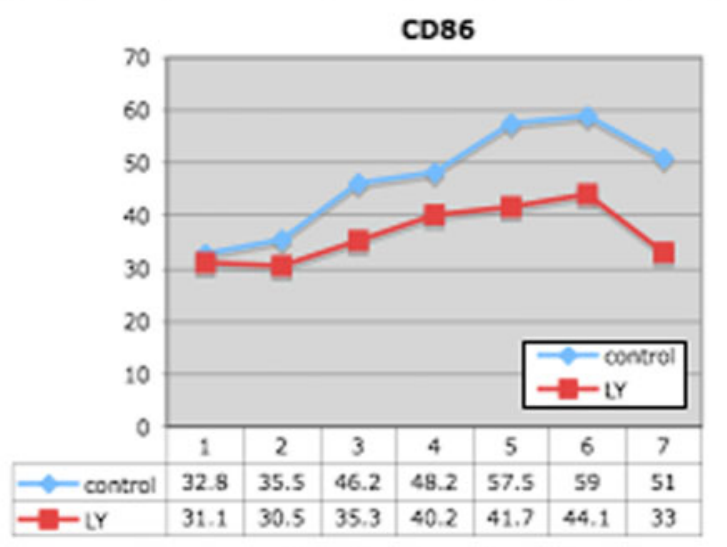

$\%$ of gated cells 
४Fig. 3 a LY-294002-generated DC segregate into CD11c-CD11b+ and $\mathrm{CD} 11 \mathrm{c}+\mathrm{CD} 11 \mathrm{~b} \pm$ population with significantly lower levels of class I and class II MHC on a per cell basis compared to control-generated DC in vitro. Compared to the segregation of control-generated DC, LY-294002-generated DC segregate into two populations, a major $\mathrm{CD} 11 \mathrm{c}+\mathrm{CD} 11 \mathrm{~b} \pm$ and a minor $\mathrm{CD} 11 \mathrm{c}-$ $\mathrm{CD} 11 \mathrm{~b}+$ population. The illustrations at the right side of the FACS quadrants in the top panels indicate the \% of day 6 bone marrowderived cells segregating into each of the quadrants representing $\mathrm{CD} 11 \mathrm{c}$ and $\mathrm{CD} 1 \mathrm{~b}$. The lower panels illustrate the mean fluorescence intensity (MFI) of class I and class II MHC on the cells segregating into each of the four quadrants representing CD11c and CD11b. The lower left panel illustrates MHC MFI on control-generated cells, and the right lower panel illustrates MHC MFI on LY-294002-generated cells. These data represent the measurement of FACS analysis means and SEM of triplicate independently generated cultures in vitro. b Continuous LY-294002 presence in GM-CSF/IL-4 DC generation cultures from murine bone marrow progenitors decreases the frequency of CD40+ and CD86+ DC as well as a decrease in the level of CD40 and CD86 on a per cell basis in vitro. By measuring the frequency of $\mathrm{CD} 40+$ and CD80+ cells on each of the days of the 6-day DC generation process, the degree of maturation of LY-294002-generated DC, determined by the \% of CD86+ and CD40+ cells, was discovered to be less than control-generated DC (right-side panel). The data are representative of three separate DC generations under the defined conditions. The values below the graph show the frequency of CD40+ or CD86+ cells (\% of cells in a gate of high forward and high side scatter cells, ascertained by FACS) measured on that day. Control indicates DC generated under standard GM-CSF/IL-4 procedure (refer to "Materials and methods"), and LY represents DC generated in the continuous presence of LY-294002. We also measured the mean fluorescence intensity (MFI) of CD86 and CD40 by FACS. The graphs (left-side panel) show the MFI of each co-stimulatory protein on cells collected at each of the days. The values below the graph show the specific MFI measured on that day. Control indicates DC generated under standard GM-CSF/IL-4 procedure (refer to "Materials and methods"), and LY represents DC generated in the continuous presence of LY-294002. The data are representative of three separate DC generations under the defined conditions. $\mathbf{c}$ CD8alpha- CD11c+ CD11b+ DC are generated under control and LY-294002 exposure in vitro with a shift of CD8alphacells into a CD11c $+\mathrm{CD} 11 \mathrm{~b}^{+/ \text {INTERMEDIATE }}$ population under LY-294002 conditions in vitro. The panel on the left shows the segregation of DC along CD11c and CD11b surface expression. CD8alpha- cells are distributed between CD11c+ $\mathrm{CD} 11 \mathrm{~b}^{\text {INTERMEDIATE }}$ and $\mathrm{CD} 11 \mathrm{c}+\mathrm{CD} 11 \mathrm{~b}^{\mathrm{HIGH}}$ populations. Under LY-294002 exposure, the frequency of CD8alpha- cells in the $\mathrm{CD} 11 \mathrm{c}+\mathrm{CD} 11 \mathrm{~b}^{\mathrm{HIGH}}$ population significantly decreases and is redistributed among CD11 $\mathrm{c}^{\text {INTERMEDIATE }} \mathrm{CD} 11 \mathrm{~b}^{\text {INTERMEDIATE }}$ cells (right-side panel). The values above the histograms represent the frequency of CD8alpha- cells inside the respective CD11c CD11b populations referred to in the FACS quadrants as a percentage of the total gated cells. The values show the mean \pm SEM of triplicate independently generated DC cultures. The FACS quadrants and histograms are representative of the triplicate cultures

that LY-294002 acts at least at two levels in the generation of immature DC in vitro: first, it suppresses the frequency of DC in vitro that differentiate into cells with significant expression of CD40 and CD86 at the cell surface; and second, it suppresses the level of these two co-stimulatory proteins on the surface of DC on a per cell basis. We did not observe any differences in CD80 relative cell surface levels or frequency of CD80+ cells in DC cultures generated in the presence of LY-294002 compared to control conditions.

The segregation of control and LY-294002-generated cells into CD11c+ and CD11b ${ }^{+/ I N T E R M E D I A T E}$ populations suggested the possibility that some of these cells could be CD8alpha- suppressive DC [81-83]. In Fig. 3c, we show that such CD8alpha- cells reside inside the CD11c+ $\mathrm{CD} 11 \mathrm{~b}+$ population in control-generated DC (left-side panel). LY-294002-generated DC do not exhibit any significant changes in the frequency of CD8alpha- CD11c+ $\mathrm{CD} 11 \mathrm{~b}+$ cells; however, most of the CD8alpha- cells segregate outside the $\mathrm{CD} 11 \mathrm{~b}^{\mathrm{HIGH}} \mathrm{CD} 11 \mathrm{c}+$ population and into a CD11 $\mathrm{b}^{\text {INTERMEDIATE }} \mathrm{CD} 11 \mathrm{c}+$ population (right-side panel, Fig. 3c).

Cytokine profiles in supernatants of LY-294002-treated DC cultures

Co-stimulation impairment has been shown to underlie many instances of DC-directed hyporesponsiveness of allogeneic and autoimmune $\mathrm{T}$-cell proliferation in vitro and in vivo [25, 70, 84, 85]. However, changes in cytokine production by DC are also known to provide additional levels of control of T-cell proliferation [86-90]. We first determined the profile of cytokines produced, as well as their concentration, in the culture supernatants of bone marrow progenitors differentiating toward DC in the presence of LY-294002 or PBS vehicle.

By Luminex assay, we did not detect any of the classical TH1-type cytokines in unstimulated control-generated DC or LY-294002-generated DC (data not shown). We then ascertained the cytokine profile and measured the cytokine levels in the supernatants of the allogeneic MLR referred to earlier (shown in Fig. 2). We identified differences in the concentrations of cytokines in DC generated in the presence of LY-294002 compared to control DC (Fig. 4; increased GM-CSF, increased IL-13, decreased IL-5, undetectable TNF-alpha, undetectable MCP-1,). Although these changes are suggestive of a shift of T-cell populations toward a state of regulatory capacity, they are not a clear cut and well-defined TH1-to-TH2 shift [91-94]. Indeed, we did not detect any significant levels of IL-1-beta, IFNgamma, IL-4, or IL-10 in the MLR supernatants nor were there any real differences between MLR co-cultures with control and PI3K-impaired DC (not shown).

PI3K-impaired DC promote a decrease in the frequency of CD4+ CD25+ Foxp3 - cells in vitro in mixed culture

The differences in cytokine profiles of MLR-derived supernatants between co-cultures with control DC and LY294002-generated DC suggested that another potential 


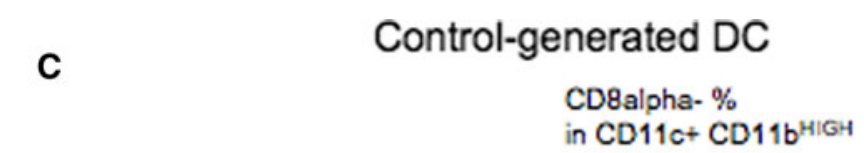

$32.6+1-0.8$

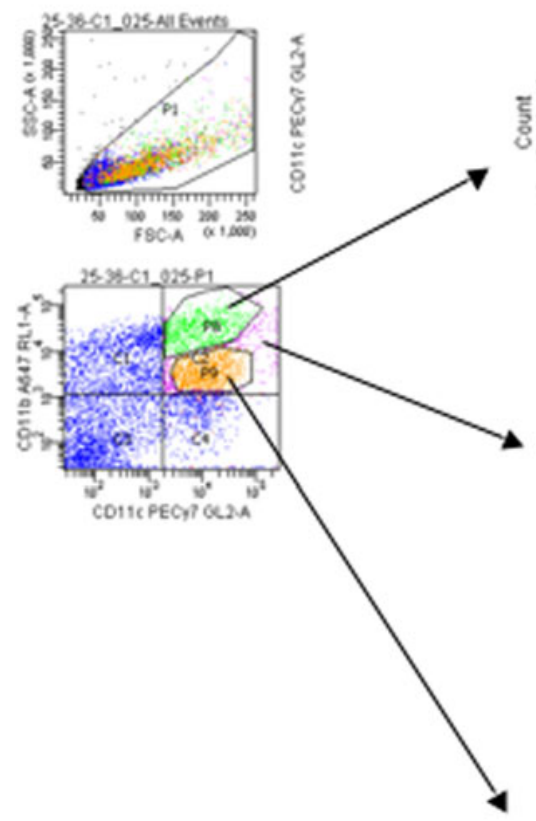

CD8alpha- \% in CD11c+CD11bINTER
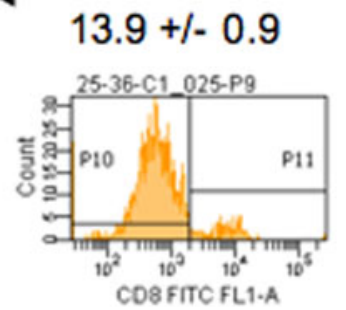

Fig. 3 continued

mechanism of impaired T-cell proliferation could involve increased regulatory $\mathrm{T}$-cell frequency or changes in the frequency of activated non-regulatory T-cells. Toward this objective, we measured the frequency of $\mathrm{CD} 4+\mathrm{CD} 25+$ as well as CD4+ CD25+ Foxp3 + cells in the co-cultures at the end of the 5-day incubation period of freshly isolated splenic T-cells and DC generated in the presence or absence of LY-294002 (Fig. 5). In Fig. 5b, we show that compared to co-cultures with control DC, LY-294002generated DC induced a decrease in the frequency of CD4+ CD25+ Foxp3 - cells (i.e. active immunocompetent T-cells). In Fig. 5c, we demonstrate that control DC elicit a significant decrease in the frequency of naive CD4+ CD25- Foxp3 - cells while LY-294002-generated DC induce a dramatic increase in the frequency of the same naive T-cell population (CD4+ CD25- Foxp3- cells). We did not observe any differences in the frequency of regulatory, immunosuppressive CD4+ CD25+ Foxp3+ cells in cultures where the DC were generated under control or LY294002 conditions (data not shown). However, in those
LY-294002-generated DC

CD8alpha- \% in $\mathrm{CD} 11 \mathrm{c}+\mathrm{CD} 11 \mathrm{~b}{ }^{\mathrm{HIGH}}$

$8.8+/-0.4$

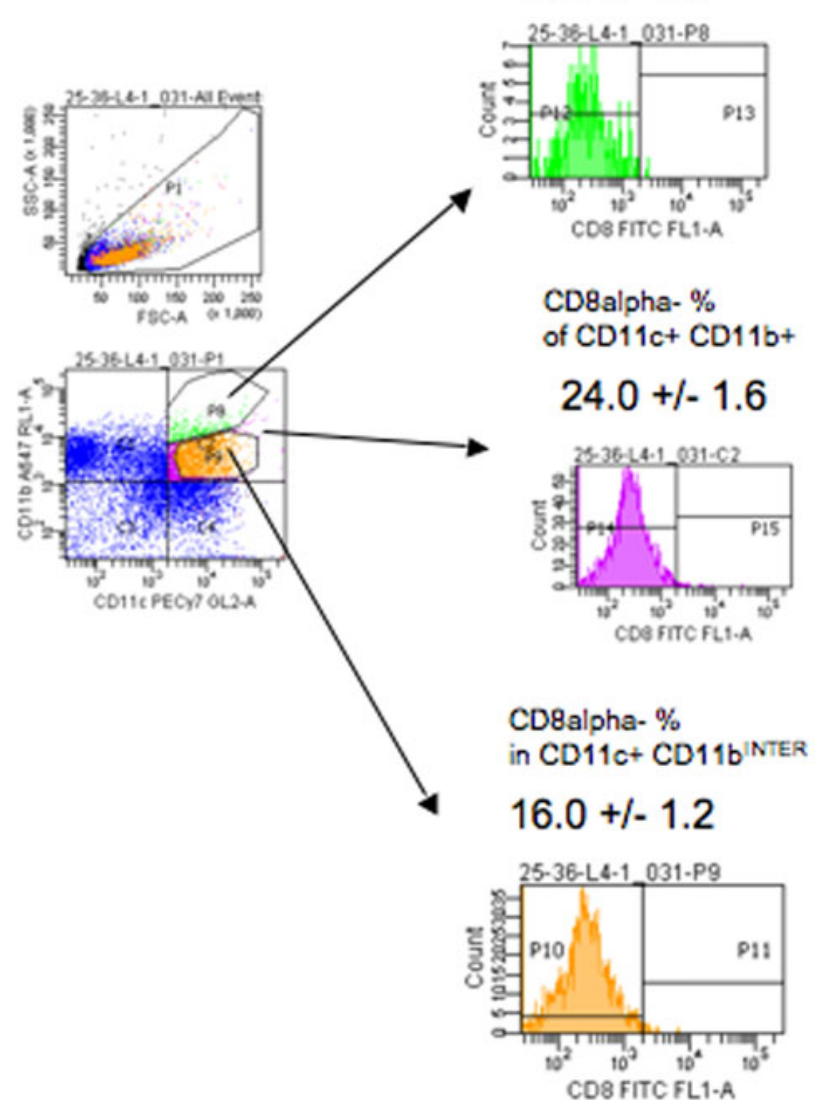

cells that did express Foxp3, we observed that control DC induce a decrease in the Foxp3 content on a per cell basis (measured indirectly by FACS in the form of mean fluorescence intensity; MFI) whereas in contrast, LY-294002 DC-co-cultured T-cells expressing Foxp3 exhibit a significant increase in the content of Foxp3 on a per cell basis (Fig. 5d). Given that the frequency of CD4+ CD25+ Foxp3+ cells was not different between control and LY294002-generated DC:T-cell co-cultures, the difference in Foxp3 content on a per cell basis very likely reflects transcriptional or post-transcriptional mechanisms of Foxp3 modulation by control and PI3K-impaired DC.

TLR9 signaling promotes immunostimulatory DC generation in vitro, even in the presence of PI3K inhibition

At this point, our data suggested that PI3K inhibition facilitates the generation of immature immunosuppressive DC in vitro. The PI3K pathway is one point of convergence 

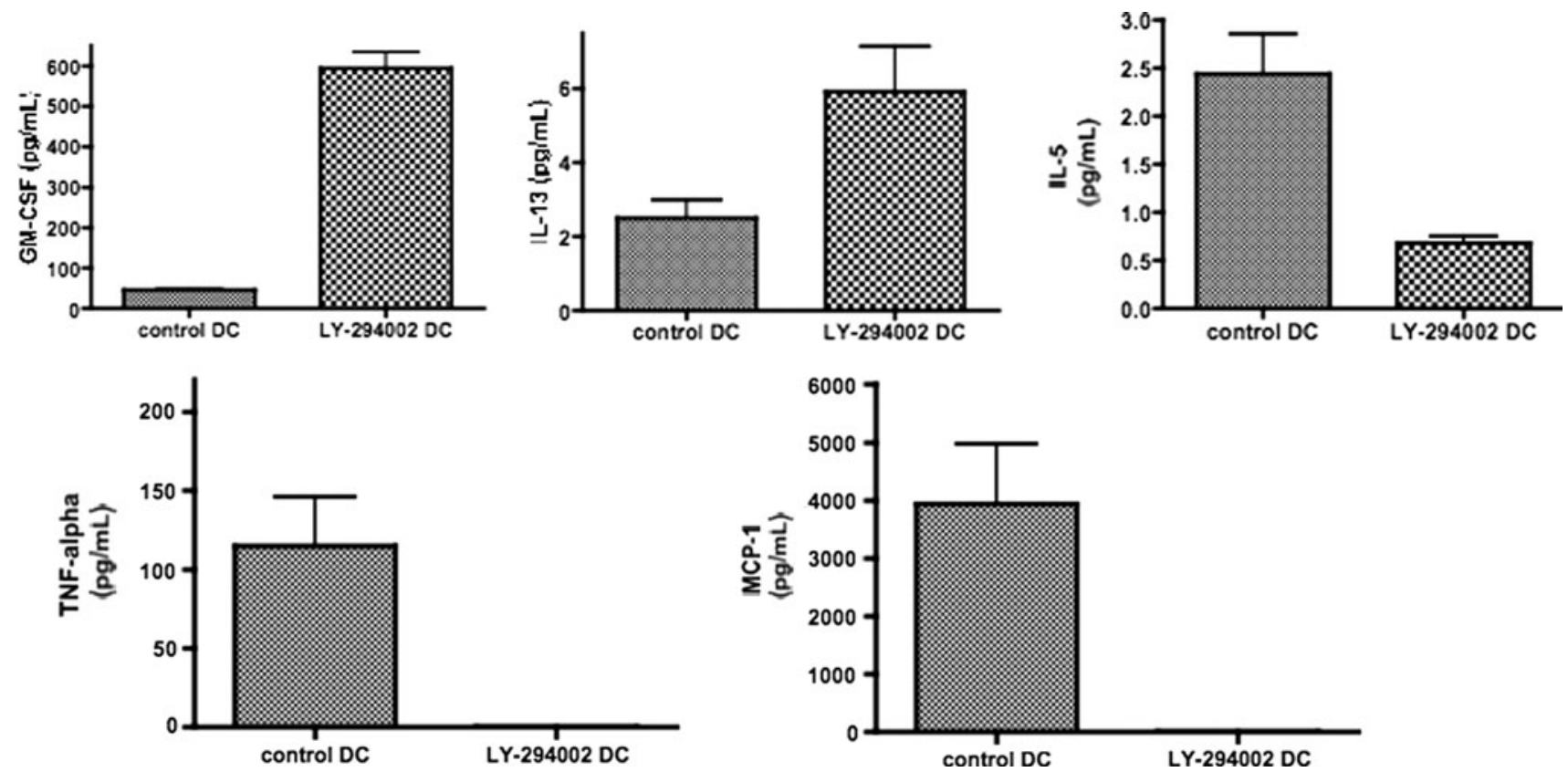

Fig. 4 Cytokine profile of supernatants from mixed leukocyte cultures of LY-294002-generated DC exhibits an immunoregulatory TH2-like phenotype. Luminex multi-analyte assay was used to measure the concentration of 22 cytokines, chemokines, and growth factors in day 5 supernatants of the mixed leukocyte reactions shown in Fig. 2. Suppression of TNF-alpha and MCP-1 with concomitant

upregulation of IL-13 is suggestive of T-cells producing cytokines that would promote a TH2-like state of immune environment. The graphs show the concentrations of each of the detectable cytokines, and the error bars represent the SEM of quintuplicate wells. The data are representative of at least two independent experiments

of TLR signals [14, 17, 20, 72, 79, 95-98]. TLR signaling often confers immunostimulatory properties to DC, and a class of DC-based vaccines in clinical consideration are in essence DC generated in the presence of, or treated at the end of culture with, $\mathrm{CpG}$ oligonucleotides which act via TLR9 [19, 63, 64, 99]. We asked whether TLR9 activation using $\mathrm{CpG}$ oligonucleotides would override the effect of $\mathrm{PI} 3 \mathrm{~K}$ inhibition and shift the balance in favor of generation of immunostimulatory DC. We repeated the experiments above; however, this time, we generated DC in the presence of LY-294002 and oligonucleotide 1826 (ODN 1826) which is one of the "classic" TLR9 agonists [63-66]. As controls, we also considered DC generated in the presence of ODN 1826 alone.

Generation of DC in the presence of ODN 1826 resulted in a segregation of cells into mostly CD11c+ CD $11 b^{-/ I N T E R M E D I A T E}$ cells with a heterogeneous distribution among CD11c and CD11b (Fig. 6a). A significant reduction in CD8alpha- CD11c+ CD11b+ cells was observed, and the levels of class I and class II MHC were no different between ODN 1826-generated DC and controlgenerated DC (refer to tables at the right side of Fig. 6a). When the DC were generated in the presence of LY-294002 and ODN 1826, at the end of the generation period, the cells segregated mainly into $\mathrm{CD} 11 \mathrm{c}^{+/ \mathrm{HIGH}} \mathrm{CD} 11 \mathrm{~b}^{\mathrm{HIGH}}$ and a $\mathrm{CD} 11 \mathrm{c}-\mathrm{CD} 11 \mathrm{~b}-$ population. The largest distribution was into the $\mathrm{CD} 11 \mathrm{c}^{+/ \mathrm{HIGH}} \mathrm{CD} 11 \mathrm{~b}^{\mathrm{HIGH}}$ population (Fig. 6a

bottom panel). The resemblance of these cells to controlgenerated DC and the low levels of class I and class II MHC suggested that they may exhibit functionally suppressive properties in allogeneic MLR in vitro. However, in Fig. 6b, we show that DC generated in the concurrent presence of the PI3K inhibitor and ODN 1826 are as stimulatory as in co-cultures where the DC were not treated during the generation period or where the $\mathrm{DC}$ were generated in the presence of the DC immunostimulatory CpG ODN 1826. In support of these data, we observed that IL-1 beta and IL- 6 were significantly increased in MLR supernatants from co-cultures of T-cells with DC generated in the presence of ODN 1826 (Fig. 6c). Although the generation of DC in the co-presence of ODN 1826 and LY-294002 elicited greater IL-1 beta production compared to ODN 1826 alone, IL-6 production was not as responsive to DC generated in the co-presence of ODN1826 and LY-294002 compared to co-cultures with DC treated only with ODN1826, suggestive of a suppressive effect of PI3K inhibition on the production of IL-6.

Effects of PI3K inhibition during the generation of DC from murine bone marrow progenitors on Akt, p38, and nuclear GSK-3 beta phosphorylation as well as NF-kappaB p65 nuclear accumulation in vitro

To gain an understanding of the signaling pathways that PI3K inhibition could affect in DC during the generation 

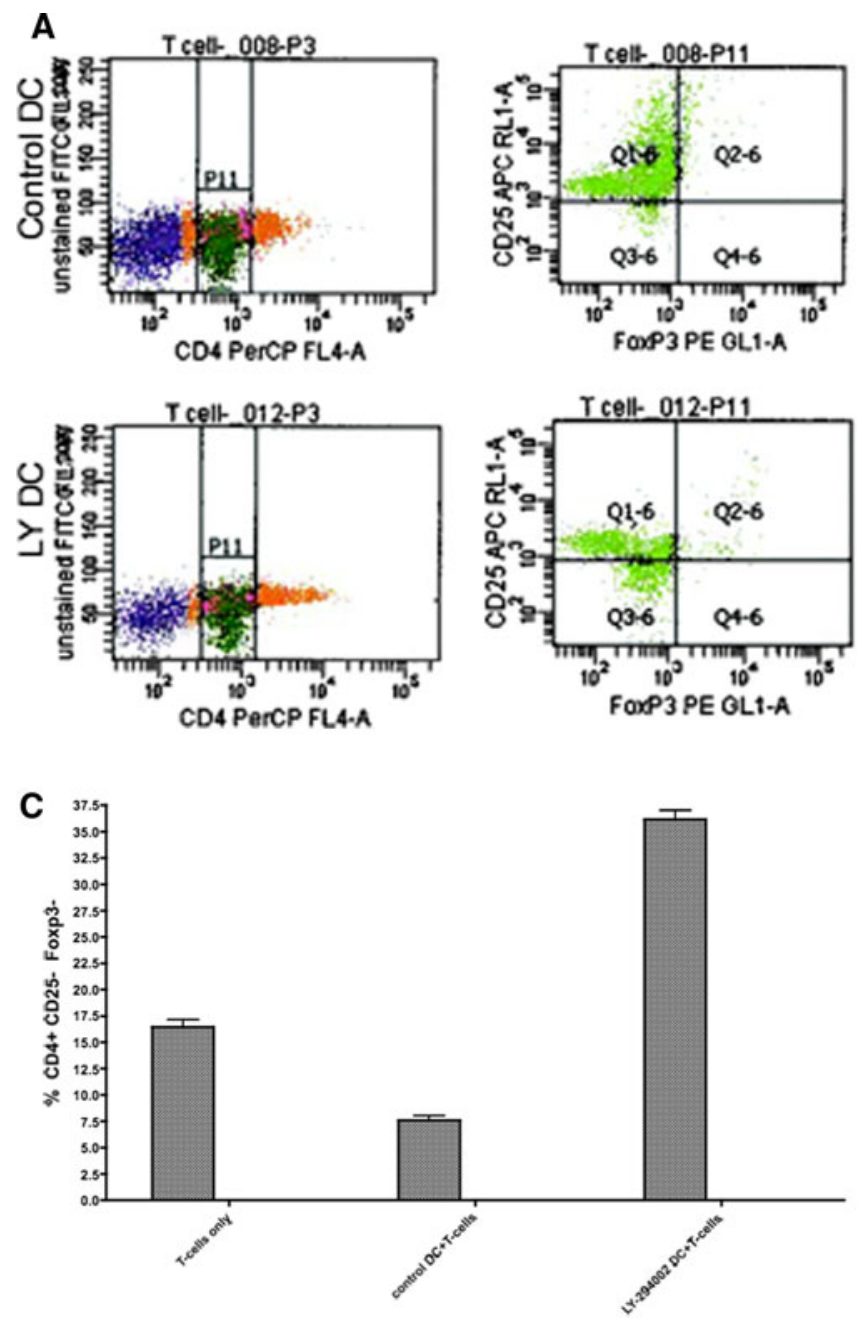

Fig. 5 LY-294002-generated DC elicit a decrease in the frequency of CD4+ CD25+ Foxp3 - cells and an increase in CD4+ CD25Foxp3- cells while slightly upregulating the level of Foxp3 in existing, but not proliferating CD4+ CD25+ Foxp3+ T-cells in mixed leukocyte reaction in culture. At the end of the 5-day MLR shown in Fig. 2, parallel co-cultures were stained with fluorescent antibodies specific for CD4, CD25, and Foxp3. The frequency of cells was measured by FACS. All graphs show the frequency of the cell population indicated on the $y$-axis of each graph and the error bars the SEM of quadruplicate wells. a The quadrants show the FACS gating criteria used to measure the frequency of the indicated cells. LY-294002-generated DC induce a shift in the population frequency of $\mathrm{CD} 4+\mathrm{CD} 25^{\mathrm{HIGH}}$ Foxp3 - cells into a population of CD4+ CD25 $5^{\text {LOW/NEGATIVE }}$ Foxp3 - cells (from quadrant 1-6 into quadrant

process, we performed Western blots to determine the phosphorylation state of PI3K downstream target Akt, p38, nuclear GSK-3 beta as well as the nuclear accumulation of NF-kappaB p65. GSK-3 beta was of particular interest given the evidence that it can modulate IL-10 expression in antigen-presenting cells and of the role of DC-derived IL-10 in immunoregulation [100].
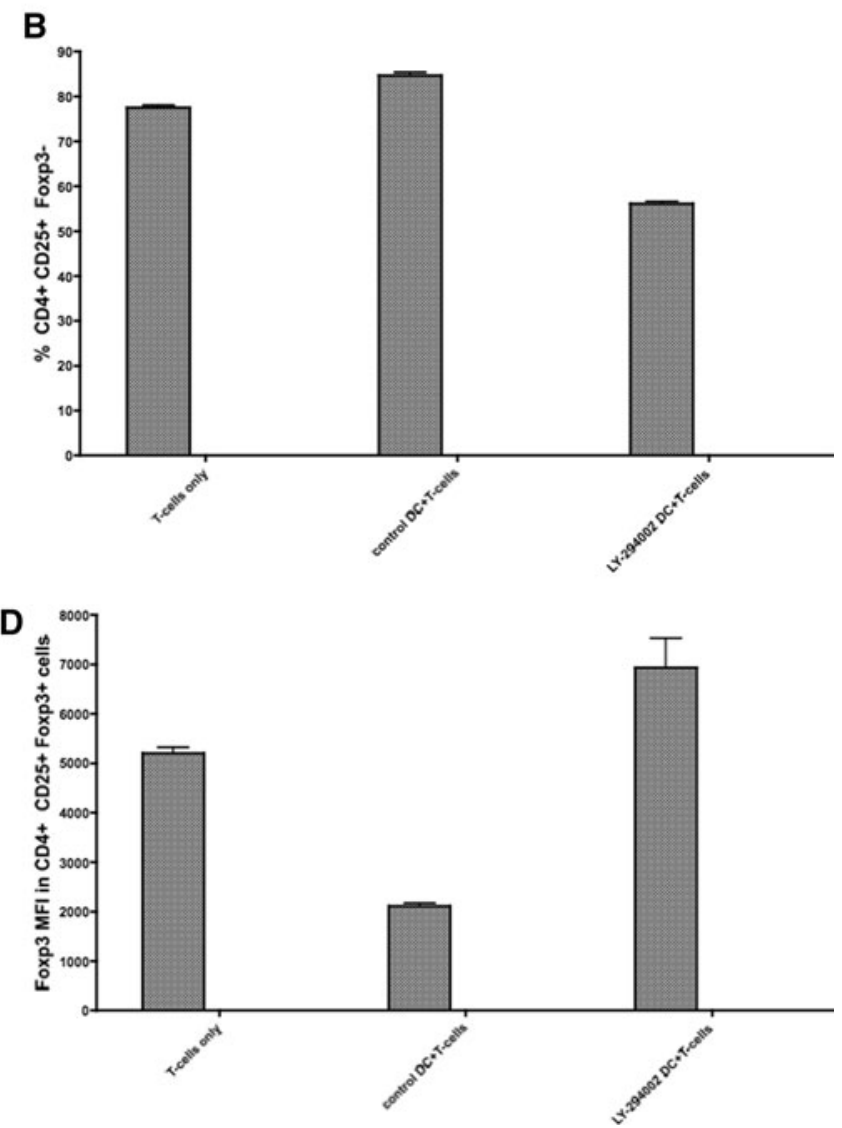

3-6). b Co-culture of LY-294002-generated DC with allogeneic T-cells results in a decrease in the frequency of CD4+ CD25+ Foxp3- T-cells. $P<0.05$ (LY-294002 DC vs. control DC:T-cell cocultures, Student's $t$ test). c Although co-culture of control DCgenerated DC with allogeneic T-cell elicited a decrease in CD4+ CD25- Foxp3- T-cells, LY-294002-generated DC induced a significant increase in the frequency of this T-cell population. $P<0.01$ (LY-294002 DC vs. control DC:T-cell co-cultures, Student's $t$ test). d Control-generated DC induced a significant decrease in the level of Foxp3 in CD4+ CD25+ Foxp3+ cells (that did not exhibit any differences in frequency compared to cultures with T-cells alone), but LY-294002-generated DC elicited an increase in Foxp3 levels in CD4+ CD25+ Foxp3+ T-cells. $P<0.01$ (LY-294002 DC vs. control DC:T-cell co-cultures, Student's $t$ test)

In Fig. 7a, we demonstrate the absence of phosphorylated Akt in differentiating $\mathrm{DC}$ in the presence of LY-294002 during all 6 days, whereas control DC exhibited phosphorylated Akt on all days (although from day 4 onward, there appears to be a slightly decreased level of phosphorylation). The absence of phosphorylated Akt in DC generated in the presence of LY-294002 is an expected 
result and confirms the inhibition of PI3K using LY294002.

We then looked at the phosphorylation of p38 MAP Kinase (p38), an important signal transducer during DC maturation which is also phosphorylated and activated in response to external proinflammatory triggers $[8,101-$ 104]. While a low, apparently basal level of phosphorylated p38 was evident in control DC on each of the days during in vitro generation, quite likely reflecting the continuous effects of culture-supplied GM-CSF signals known to stimulate p38 [105-108], in Fig. 7b, we show that the level of p38 phosphorylation in DC generated in the presence of LY-294002 was elevated.

Dendritic cells generated in vitro normally exhibit detectable levels of nuclear NF-kappaB and basal NFkappaB activity which is important in cell survival and maintenance of a state where DC facilely take up exogenous molecules and express basal co-stimulatory proteins. Upon encountering proinflammatory signals, such as TLR agonists, NF-kappaB nuclear accumulation dramatically increases, and the transcription of genes important in the maturation and the capacity to provide co-stimulation to T-cells is substantially augmented $[8,109,110]$. To determine whether PI3K inhibition affected NF-kappaB nuclear levels in differentiating DC, we ascertained the nuclear levels of NF-kappaB p65 in DC generated under control conditions or LY-294002. In Fig. 7c, we show that p65 NF-kappaB is detectable in nuclear extracts of control and LY-294002-generated DC; however, starting on day 3, the levels of p65 in LY-294002-generated DC are significantly reduced and are apparently maintained at this level until the end of the generation period (Fig. 7c).

A number of studies indicate that, just like NF-kappaB, GSK-3 beta is a transcription factor responsive to TLR signals which can play an important role in shifting an antigen-presenting cell's phenotype from that of a potent immunostimulator to a cell that can induce immunosuppression [97, 100, 111, 112]. A number of studies confirm that GSK-3 beta regulates IL-10 gene expression [100, 113-115], and DC that express IL-10 can shift a T-cell response from a proinflammatory $\mathrm{TH} 1$ to a regulatory $\mathrm{TH} 2$ type $[116,117]$. Phosphorylation of GSK-3 beta renders it inactive, whereas the unphosphorylated form is transcriptionally active $[118,119]$. It was of interest, therefore, to establish the co-accumulation pattern of nuclear NF-kappaB p65 and phospho-GSK-3 beta in DC generated from bone marrow progenitors every day during the generation period under control or LY-294002 conditions. In Fig. 7d, we show a progressive decline in nuclear phospho-GSK-3 beta levels under control conditions, starting on day 2 . However, in LY-294002-generated DC, we demonstrate a stable level of nuclear phospho-GSK-3 beta and at levels higher than DC generated under control conditions. p38 phosphorylation is suppressed during the generation of PI3K-impaired DC in the presence of sustained TLR9 signaling

We then sought to identify the changes in phosphorylation of the proteins outlined above in DC generated in the co-presence of LY-294002 and ODN 1826, a well-known TLR9 agonist. In Fig. 8a, we show that, as expected, generation of DC in the continuous presence of ODN 1826 alone maintained phospho-Akt to levels similar to those in control-generated DC. However, phospho-p38 was almost absent at all days when DC were generated in the continuous presence of ODN 1826 compared to the level in control DC (Fig. 8a). Nuclear phospho-GSK-3 beta levels were also increased in DC generated in the presence of ODN 1826 alone compared to control-generated DC (Fig. 8b). We show that the levels of phospho-Akt were barely discernible at all days during DC generation in the presence of LY-294002 even when ODN 1826 was included for all days compared to control-generated DC (Fig. 8c). The co-inclusion of ODN 1826 with LY-294002 during the $\mathrm{DC}$ generation period resulted in a more pronounced and progressive loss of phospho-p38 compared to control-generated DC (Fig. 8d). Nuclear phospho-GSK-3 beta levels, in DC generated in the co-presence of LY294002 and ODN 1826, were no different than in control condition-generated DC; however, we believe that this represents degradation of GSK-3 beta in the LY-294002/ ODN 1826-generated DC and not differences in the phosphorylation state (compare GSK-3 beta protein levels between control- and LY-294002/ODN 1826-generated DC in Fig. 8e).

PI3K inhibition in post-generation DC increases the immunostimulatory activity of DC in vitro which is potentiated by a TLR9 agonist oligonucleotide

It is important to note that most of the ex vivo generated DC for use in human immunotherapy are treated postgeneration (i.e. starting on day 6 or 7 of culture) with maturation or modulation agents such as TNF-alpha, $\mathrm{PGE}_{2}$, CpG oligonucleotides [120-122]. We therefore asked whether adding LY-294002 with or without ODN 1826 in post-generated DC cultures (i.e. adding the LY-294002 and/or ODN 1826 at the end of the DC generation period; starting on day 6 in GM-CSF/IL-4-generated DC) would confer to the DC different immune stimulation capacity as well as differences in the phosphorylation of the proteins listed earlier compared to DC generated in the presence of LY-294002/ODN 1826.

In these experiments, the DC were washed free of the LY-294002 and/or ODN 1826 prior to transfer to allogeneic T-cell cultures. Unlike the immunsuppressive character of 
A
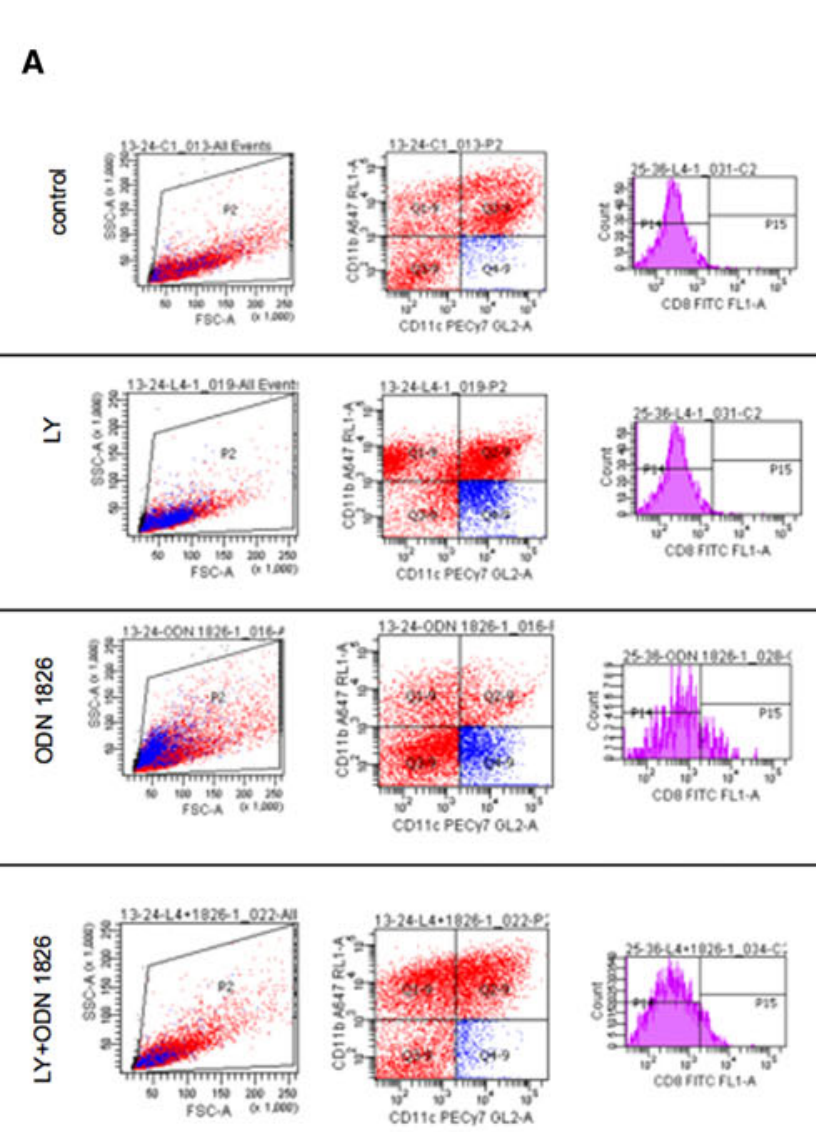

$30.2+1 \cdot 2.0$

MFI in
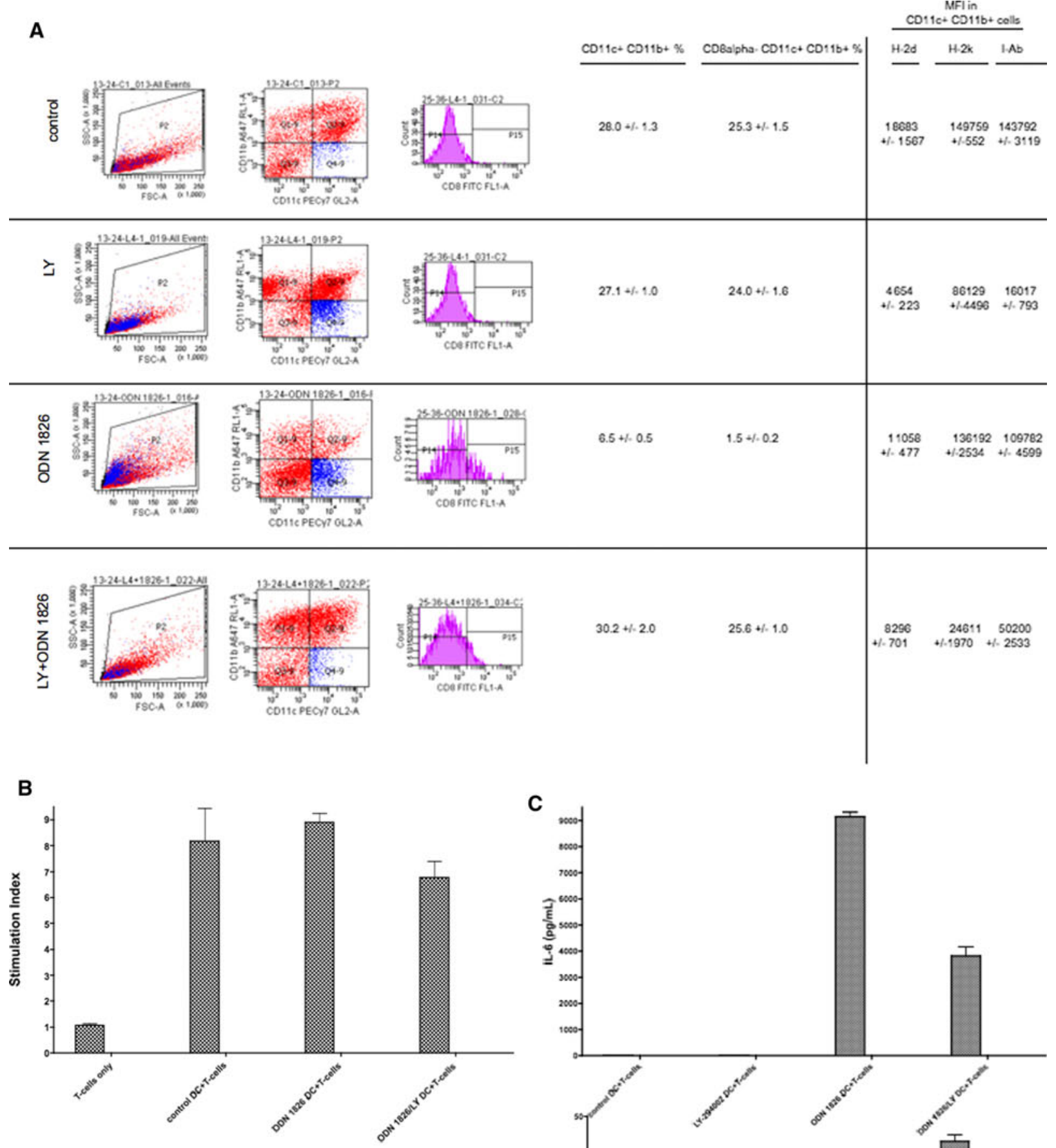

C

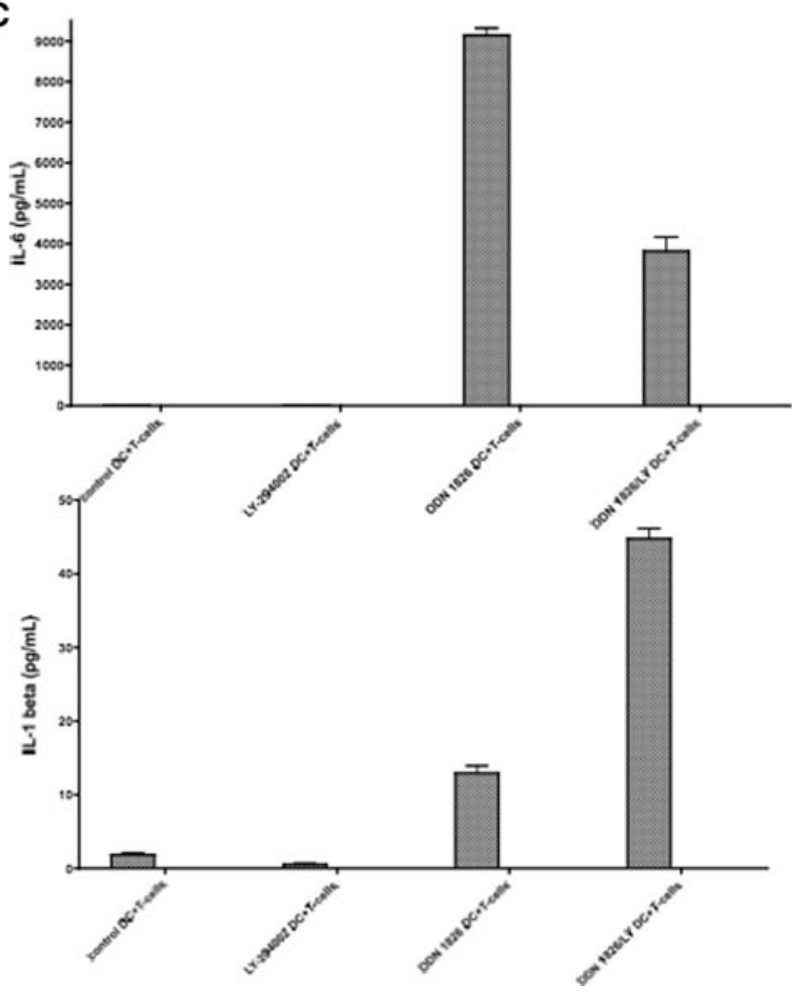


4 Fig. 6 TLR9 agonist CpG ODN 1826 overrides the effects of LY294002 in generating immunosuppressive DC from bone marrow progenitors. a Shown are the FACS quadrants in which cells with CD11c and CD11b surface expression were identified, forward versus side scatter and historams showing the levels and frequency of CD8alpha - cells inside a CD11c+CD11b+ population. The tables summarise the frequency of CD11c+CD11b+ cells as a percentage of total cells, CD8alpha- CD11c+CD11b + cells as a percentage of total cells as well as the MFI of class I and class II MHC on CD11c+ $\mathrm{CD} 11 \mathrm{~b}+$ cells. Data are shown for the phenotypes of day $6 \mathrm{DC}$ generated under control, LY-294002 (LY), ODN 1826 and combined LY/ODN 1826 conditions. The measurements indicate the mean \pm SEM of quadruplicate independent cultures. b DC were generated in GM-CSF/IL-4 in the presence or absence of ODN 1826 and the combination of ODN 1826 and LY-294002. At the end of the DC generation, LY-294002 and ODN 1826 were washed off, and the cells were further washed extensively. The DC were collected on day 7 and added to allogeneic splenic T-cells in vitro. At the end of the 5 day MLR, the cultures were pulsed with BrdU, and after an overnight incubation, the frequency of BrdU+ cells (representing proliferating cell frequency) was measured by FACS. The graph shows the frequency of proliferating cells as a stimulation index $(S I)$. The SI was calculated by dividing the proliferation of T-cells in the different cocultures by background proliferation. Proliferation observed in cultures of T-cells only was considered to be the background level and assigned a value of 1 . The bars represent the means, and the error bars represent the SEM of quadruplicate wells. $P<0.05$ by ANOVA (one-tailed) comparing proliferation of allogeneic T-cells in coculture with control-generated DC, ODN 1826-generated DC and LY294002-generated DC. c The culture supernatants from the day 5 allogeneic MLR were collected, and the cytokine profiles were identified along with the measurement of concentrations of the detectable cytokines. IL- 6 and IL- 1 beta were detected only in the MLR supernatants of co-cultures with ODN 1826-generated DC and allogeneic T-cells and ODN 1826/LY-294002-generated DC cocultures. The bars represent the means of the cytokine concentrations and the error bars the SEM of quadruplicate wells. $P<0.05$ by ANOVA (one-tailed) comparing cytokine concentrations from cultures of allogeneic T-cells in co-culture with control-generated DC, ODN 1826-generated DC, and LY-294002-generated DC

the DC generated in the presence of LY-294002 continuously during the DC differentiation culture protocol, the cells treated with the PI3K inhibitor beginning on day 6 (post-generation) exhibited an increased capacity to stimulate allogeneic T-cell proliferation in vitro (Fig. 9a). Furthermore, we also detected a significant increase in the MLR supernatant concentrations of TNF-alpha (Fig. 9b) when DC were treated with LY-294002 post-generation. Co-treatment of the DC with LY-294002 and ODN1826 beginning at the end of the GM-CSF/IL-4 generation period potentiated their stimulatory effect on allogeneic T-cell proliferation (Fig. 9c) and resulted in an increase in IL-6, IL-12p70, and IL-13 concentrations in the allogeneic MLR supernatants (Fig. 9d). We did not detect any changes in the frequency of any of the T-cell populations listed earlier and shown in Figs. 5ad (data not shown) compared to co-cultures with control DC. Last, although the levels of phospho-Akt were barely detectable, the levels of phosphorylated p38, nuclear phospho-GSK-3 beta, and nuclear NF-kappaB p65 were not significantly different in DC treated with LY-294002 on day 6 compared to day 6 control (untreated) DC (data not shown). The addition of ODN 1826 to these LY294002-treated day 6 DC also did not affect the phosphorylation of p38 or nuclear GSK-3 beta to any degree significantly greater than in ODN 1826 -treated day 6 , postgeneration DC (data not shown).

\section{Discussion}

$\mathrm{PI} 3 \mathrm{~K}$ is an important signaling protein for many cellular processes. In hematopoietic cells as well as almost all immune cells, it acts as one key convergence point of multiple signaling pathways including those for growth factor receptors, cytokine receptors and pattern recognition proteins such as the TLRs $[1,11,21]$. From this point of convergence, PI3K signaling projects to multiple and interrelated horizontally and vertically integrated intracellular signaling networks, most often in a crosstalk manner. This crosstalk adds to the complexity toward a complete understanding of PI3K-specific effects, other than its wellestablished effect in promoting the phosphorylation and subsequent activation of Akt $[10,11,123]$. While PI3KAkt signaling has best been associated with cell survival through its effects in the upregulation of a number of antiapoptotic molecules [16, 73, 80, 124, 125], less effort has been applied to understand its other possible roles, especially in DC.

In this report, we show that sustained PI3K inhibition in bone marrow progenitors differentiating toward DC under the effects of GM-CSF and IL-4 results in the generation of immature, immunosuppressive DC. These DC, by virtue of their CD8alpha- CD11c+ CD11b+ surface phenotype, resemble previously reported immunosuppressive DC [81-83]. This observation is of obvious clinical significance especially as immunosuppressive DC are now in the investigational stage of clinical study to treat autoimmunity and have long been considered as cell therapeutics to facilitate allograft survival [33]. PI3K inhibition during the process of DC generation, in our experience, was not associated with apoptosis or impaired cell survival at levels higher than routinely observed in generating DC from bone marrow progenitors, although some reports indicate that DC exposure to PI3K inhibitors promotes apoptosis [126-129]. This may reflect species-specific effects or that PI3K inhibition during DC generation does not affect cell survival. Our data also demonstrate that it is possible to override a PI3K-impaired, immunosuppressive state in DC by provision of a TLR signal, in our case- $\mathrm{CpG}$ oligonucleotides acting through TLR9. Furthermore, we show that the timing of PI3K inhibition is important in dictating the outcome of DC phenotype. When PI3K is inhibited in a 


\section{A Control DC}

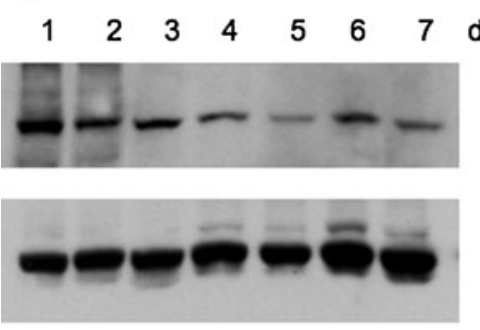

Akt
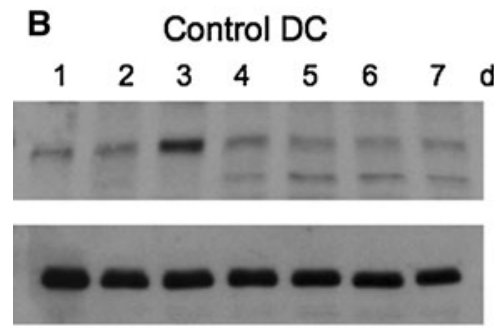

\section{days}

Phospho-p38

p38

\section{Control DC}

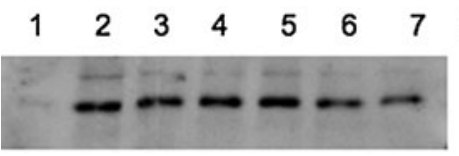

days

\section{NF-kappaB \\ P65}

(nuclear)

\section{LY-294002-generated DC}
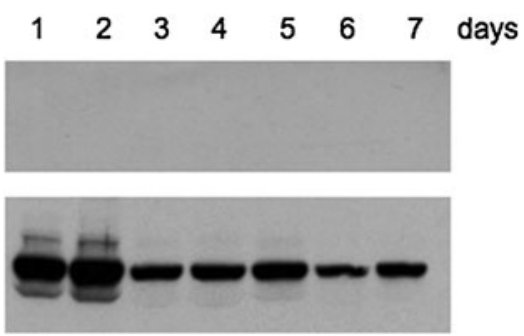

\section{LY-294002-generated DC}
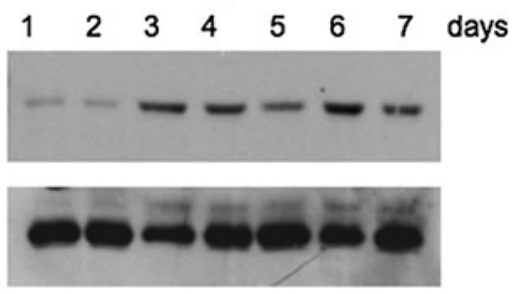

LY-294002-generated DC
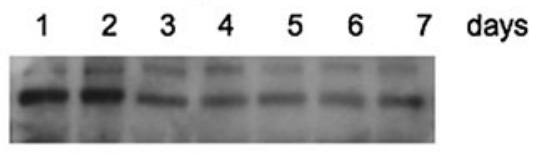

LY-294002-generated DC

D Control DC

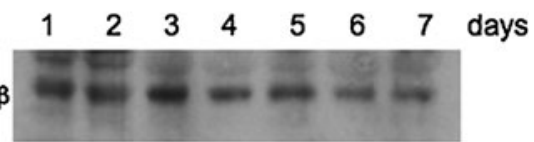

Phospho-
(nuclear)

Nuclear GSK-3 $\beta$

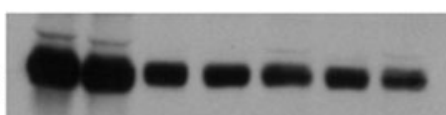

Fig. 7 Phosphorylation patterns of Akt, p38, and nuclear GSK-3 beta as well as nuclear levels of NF-kappaB p65 in control- and LY294002-generated DC in vitro. DC generated from murine bone progenitors under standard GM-CSF/IL-4 conditions with or without the addition of LY-294002 throughout the generation process were collected on day 7 . The cells were processed to obtain a cytosolic or nuclear fraction. The proteins in the fractions were resolved electrophoretically in SDS-PAGE gels, and the specific phosphoproteins were identified in western blots using phospho-specific antibodies. As controls, antibodies specific for the unphosphorylated proteins were used to probe parallel blots. The data are representative of two DC preparations under each condition. a Phosphorylated Akt is undetectable in LY-294-002-generated DC at all days of the generation process in vitro (right-side panels) compared to the levels of phospho-Akt in control-generated DC (left panels). The lower panels show the total levels of Akt in the DC at each day of the generation process. b Phosphorylated p38 levels increase to reach an apparent steady amount by day 3 in LY-294002-generated DC (rightside panel) compared to control-generated DC (left-side panel) which exhibit a sharp increase in phospho-p38 on day 3 and return to day 1

sustained manner during the generation of DC, immunosuppressive cells develop. PI3K inhibition resulted in DC that expressed low levels of CD86 and CD40 and levels between day 4 and the day of DC collection for analysis. The lower panels show the total levels of p38 in the DC at each day of the generation process. $\mathbf{c}$ NF-kappaB p65 is found at lower amounts in the nuclei of LY-294002-generated DC compared to control-generated DC. NF-kappaB p65 is not detectable on day 1 in DC differentiation in GM-CSF/IL-4, but is evident on day 2 and is stable at that level for every remaining day (left-side panel). In contrast, LY-294002 exposure of the differentiating DC elicits nuclear p65 accumulation on day 1 which drops on day 3 to a stably similar level between days 4 and 7 (right-side panel). d LY-294002 prevents the downregulation of nuclear phospho-GSK-3 beta in DC differentiating in vitro from GM-CSF/IL-4-cultured murine bone marrow progenitors. In contrast to LY-294002-generated DC (right-side panel), nuclear levels of phospho-GSK-3 beta exhibit a dramatic decrease starting on day 4 to barely detectable levels by the end of the culture period (left-side panel). Phospho-GSK-3 beta levels appear stable across all days of the DC generation process in the presence of LY-294002 (right-side panel). The lower panels show the total levels of GSK-3 beta in the $\mathrm{DC}$ at each day of the generation process

production of lower concentrations of proinflammatory cytokines in vitro. Furthermore, generation of DC in the presence of the PI3K inhibitor resulted in substantially 
lower levels of class I and class II MHC on the surface. Additionally, these DC significantly decreased the frequency of CD4+ CD25- T-cells in vitro, possibly due to poor MHC-dependent antigen presentation, poor co-stimulation, and an absence of potent immunostimulatory cytokines. In contrast, PI3K inhibition initiated in fully differentiated DC was slightly immunostimulatory.

Although we did not exhaustively determine the levels of all possible DC surface markers, our interest in immunoregulatory DC prompted us to explore more general phenotypes. LY-294002-generated DC segregated into two distinguishable populations compared to control-generated DC. Control-generated DC were more heterogeneous in terms of $\mathrm{CD} 11 \mathrm{c}+\mathrm{CD} 11 \mathrm{~b}+$ cell prevalence, whereas LY294002-generated DC diverged into minor constituent $\mathrm{CD} 11 \mathrm{c}-\mathrm{CD} 11 \mathrm{~b}+$ and a predominant $\mathrm{CD} 11 \mathrm{c}+\mathrm{CD} 11 \mathrm{~b}+$ population. Although a Gaussian distribution of class I and class II MHC+ cells was evident in LY-294002-generated DC compared to control-generated DC, the levels of class I and class II MHC on a per cell basis were significantly lower in LY-294002-generated DC.

We noted that LY-294002-generated DC also segregate predominantly into a $\mathrm{CD} 11 \mathrm{c}+\mathrm{CD} 8 \mathrm{alph}-$ population, whereas control-generated DC represented a heterogeneous population of CD11c+ CD8alpha+ and CD11c+ CD8alpha- cells. LY-294002-generated DC shifted CD8alphacells into a CD11c + CD $11 b^{\text {HIGH/INTERMEDIATE }}$ population compared to control-generated DC although the shift toward a CD11 $b^{\text {INTERMEDIATE }}$ state in LY-294002-generated $\mathrm{CD} 11 \mathrm{c}+\mathrm{DC}$ resulted in co-segregation of the majority of CD8alpha - cells into this CD11c + CD11 $b^{\text {INTERMEDIATE }}$ population.

Even as the LY-294002-generated DC express a CD8alpha- CD11c+ CD11b+ phenotype resembling already-described immunosuppressive DC [81-83], they did not promote Foxp3+ Treg expansion unlike previous reports $[81,82]$ although the levels of Foxp3 in CD4+ CD25+ Foxp3+ cells were increased on a per cell basis. We also observed a minor population of CD11c- class I $\mathrm{MHC}^{\mathrm{LOW}}$ cells generated from bone marrow progenitors in the presence of LY-294002 which could represent an additional regulatory cell type [83]. An additional feature of the LY-294002-generated DC was their production, in vitro, of GM-CSF. This cytokine has been reported by others to increase the frequency of CD8alpha- CD11c+ CD11b+ DC which express TGFbeta and IL-10 [81]. However, unlike those reports, we were unable to detect TGFbeta or IL-10 in the supernatants of the LY-294002generated DC. It is possible that our immunosuppressive DC represent a population of metastable DC that overlap with the developmental stage and capacity of other previously characterised CD8alpha- DC, although distinct in other features and activities.
We propose that PI3K serves as a checkpoint during DC differentiation whose activity level can balance a shift between an immunosuppressive versus an immunostimulatory phenotype especially early during DC differentiation from monocyte progenitors, or in immature DC in vivo.

We discovered a considerable level of complexity as we examined PI3K-relevant intracellular signaling in murine bone marrow progenitors differentiating toward DC in vitro in conditions of sustained PI3K inhibition with or without sustained TLR9 signaling using a well-defined CpG oligonucleotide. We confirmed PI3K inhibition by the observation that Akt phosphorylation was absent at all days during DC generation. Concurrently, we observed that in PI3K-impaired DC, p38 phosphorylation was elevated. PI3K is known to act on the p38 signaling pathway upstream of p38 itself, quite possibly at the level of MKK3/ $6[16,130]$. One possible interpretation of our data could be that PI3K would act on kinases upstream of p38 and would thus act as a negative regulator of $\mathrm{p} 38$ phosphorylation. PI3K inhibition would therefore be permissive for p38 phosphorylation. In fact, Berra et al. [131] presented data suggesting that PI3K/Akt signaling antagonises p38 activation and subsequent apoptosis induction. Similarly, in endothelial cells, VEGF activates the PI3K/Akt signaling pathway to prevent apoptosis by downregulation of the p38 signaling pathway [132]. Mechanistically, Akt has been shown to form a stable complex with p38 in human neutrophils [130]. In light of our data and these observations, it is possible that PI3K signals to the $\mathrm{p} 38$ pathway to maintain low levels of p38 phosphorylation and that with DC differentiation, PI3K signaling via Akt decreases, acting in a permissive manner to facilitate increased p38 phosphorylation. Our data (Figs. 7a, b) are potentially compatible with such a mechanism, especially since PI3K inhibition results in significant increases in the levels of phospho-p38 (Fig. 7b). As such, we propose that during DC differentiation in vitro, in the presence of IL-4 and GM-CSF, p38 activity conditions the cells to maintain an immature state (p38 phosphorylation is evident in day 1 bone marrow progenitors differentiating toward DC; Fig. 7b). PI3K regulates the phosphorylation of p38 (maintains low phospho-p38 levels), and therefore, PI3K, as a potential regulator, could define the balance between immunosuppressive versus immunostimulatory DC. When $\mathrm{PI} 3 \mathrm{~K}$ activity is impaired, p38 activity increases and this further shifts the balance of the DC phenotype toward cells with low levels of CD40 and CD86 cell surface co-stimulatory proteins as well as cells that produce low concentrations of proinflammatory cytokines. What the signals are that maintain p38 in a phosphorylated state in immature DC and how these relate to low levels of CD40 and CD86 costimulatory proteins at the cell surface as well as low to absent proinflammatory cytokine production is unclear, 


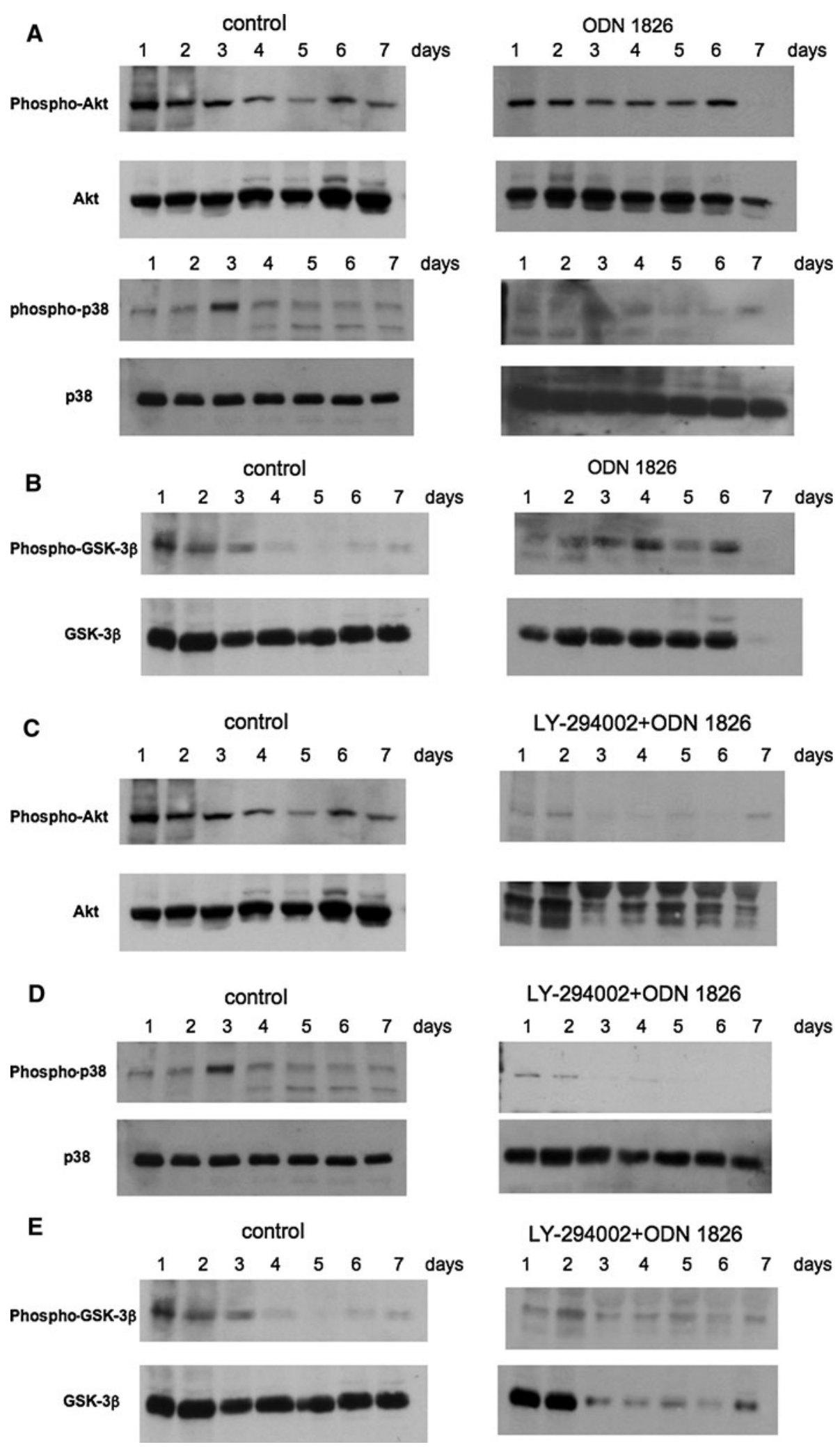

although NF-kappaB p65 is detectable in the nucleus as early as day 2 during the generation of DC and at a sustained levels from that time until DC harvest (Fig. 7c).
NF-kappaB is known to transactivate the expression of CD86, CD40 and a number of proinflammatory cytokines $[133,134]$. 
4 Fig. 8 Phosphorylation patterns of Akt, p38, and nuclear GSK-3 beta in DC generated from murine bone marrow progenitors in the coninuous presence of an immunostimulatory $\mathrm{CpG}$ oligodeoxyribonucleotide (ODN 1826) with or without LY-294002. DC generated from murine bone progenitors under standard GM-CSF/IL-4 conditions, with or without the addition of LY-294002 and/or ODN 1826 throughout the generation process, were collected on day 7 . The cells were processed to obtain a cytosolic or nuclear fraction. The proteins in the fractions were resolved electrophoretically in SDS-PAGE gels, and the specific phosphoproteins were identified in western blots using phospho-specific antibodies. As controls, antibodies specific for the unphosphorylated proteins were used to probe parallel blots. The data are representative of two DC preparations under each condition. a No differences in the level of phospho-Akt at all days in control- or ODN 1826-generated DC with the exception of undetectable phospho-Akt on day 7 of ODN 1826-generated DC (right-side upper panel). The lower panels indicate phospho-p38 at all days of generating DC. A significant increase in the level of phospho p38 is apparent on day 3 in control-generated DC (lower left panels), but otherwise, there is no clear difference in the phospho-p38 content of control- versus LY-294002-generated DC (lower panels). b ODN 1826-generated DC exhibit detectable levels of nuclear phosphoGSK-3 beta between days 2 and 6 (right-side panel) in contrast to control-generated DC where phospho-GSK-3 beta becomes undetectable from day 4 onward. c Phospho-Akt is weakly detectable in DC generated in the co-presence of LY-294002 and ODN 1826 (rightside panel) compared to control-generated DC (left-side panel). d Phospho-p38 is detectable on days 1 and 2 in DC generated in the co-presence of LY-294002 and ODN 1826 (right-side panel) compared to control-generated DC (left-side panel) where its level is prominent on day 3 but returns to a stable level equal to that of days 1-2 for the remainder of the culture period (days 4-7). e A low, but steady level of nuclear phospho-GSK-3 beta is evident across all days of culture in DC generated in the co-presence of LY-294002 and ODN 1826 (right-side panel) compared to control-generated DC (leftside panel) where the phosphoprotein becomes barely detectable starting on day 4

Another potential level of signaling control in DCgenerated in vitro which could determine the balance between immunosuppressive versus immunostimulatory DC rests with GSK-3 beta. In the unphosphorylated state, GSK-3 beta acts as a transcriptional repressor $[115,118]$ and has been shown to prevent the expression of IL-10 $[112,115]$. When phosphorylated, GSK-3 beta cannot inhibit CREB-dependent expression of IL-10 [112, 115] partly due to the decreased ability of NF-kappaB to interact with CREB and inhibit its transcriptional activity. PI3K has been proposed as one of the signaling pathways that can alter GSK-3 beta phosphorylation and activity [112, 115]. For example, Martin et al. [100, 112] have suggested that PI3K-dependent Akt can phosphorylate GSK-3 beta in response to TLR signaling and therefore downregulate its transcriptional repressive effects resulting in the production of IL-10 in peripheral blood mononuclear cells [100, 112]. Our data are consistent with such a PI3K-sensitive outcome on GSK-3 beta in DC-generated in vitro since DC generated under control conditions exhibit a steady decrease in phospho-GSK-3 beta (Fig. 7d) while DC generated under conditions of PI3K inhibition exhibit a relatively constant level of phospho-GSK-3 beta at levels higher than control DC (Fig. 7d). GSK-3 beta could therefore be another target of PI3K during DC generation that together with $\mathrm{p} 38$ could be part of a PI3K-controlled circuit of DC differentiation shifting the balance along an immunosuppressive or immunostimulatory pathway. In support of such a mechanism, we also show that DC generated under control conditions exhibit a steady level of nuclear NF-kappaB p65 at all days in culture, whereas PI3K-impaired DC exhibit a detectable, but significantly lower nuclear accumulation of NF-kappaB p65, an observation in line with a potential GSK-3 beta-mediated mechanism of transcriptional modulation [135-137].

Our data indicate that sustained TLR9 signaling in differentiating DC can override the effect of PI3K inhibition on allostimulation (Fig. 6b). We also show that sustained TLR9 signaling in the presence of LY-294002 in differentiating DC results in a very low level of phospho-p38 and nuclear phospho-GSK-3 beta, although the significant decline (by day 3) in GSK-3 beta protein levels (shown in Fig. 8e) is suggestive of degradation of GSK-3 beta and/or nuclear exclusion of the protein rather than a well-defined change in its phosphorylation state. TLR9 stimulation in the absence of any other modifier in DC often results in the phosphorylation of p38 and, as indicated above, in the phosphorylation of GSK-3 beta. That PI3K inhibition downregulates phosphorylation of $\mathrm{p} 38$ in the presence of a TLR9 agonist suggests that PI3K plays a more significant role in TLR9 signaling on the p38 pathway in DC than originally considered [138-140] and that the interplay between PI3K and p38, largely defined by PI3K activity, could determine the outcome of DC differentiation or balance toward an immunosuppressive or an immunostimulatory state. Such a possibility is supported by our finding that nuclear levels of phospho-GSK-3 beta are significantly reduced in DC generated in the presence of LY-294002 and ODN1826 (Fig. 8e).

It is interesting that PI3K inhibition during the DC generation process from bone marrow progenitors in GMCSF and IL-4 promotes immunosuppressive DC, whereas inhibition initiated in post-generated DC (i.e. LY-294002 addition on day 6 of the DC cultures) has a slight immunostimulatory effect (compare Fig. 6b with Fig. 2). This suggests that PI3K may play a regulatory role during DC development and differentiation, but that in differentiated cells, other signaling pathways override and/or are more instrumental in conferring a functional phenotype to DC.

In sum, it is evident that the signaling components and their regulation during the process of DC generation from bone marrow progenitors of mice are complex. We anticipate a similar situation for human DC. Our data suggest that $\mathrm{PI} 3 \mathrm{~K}$ could be one of a series of important regulators that determine the degree of DC immunocompetence and 

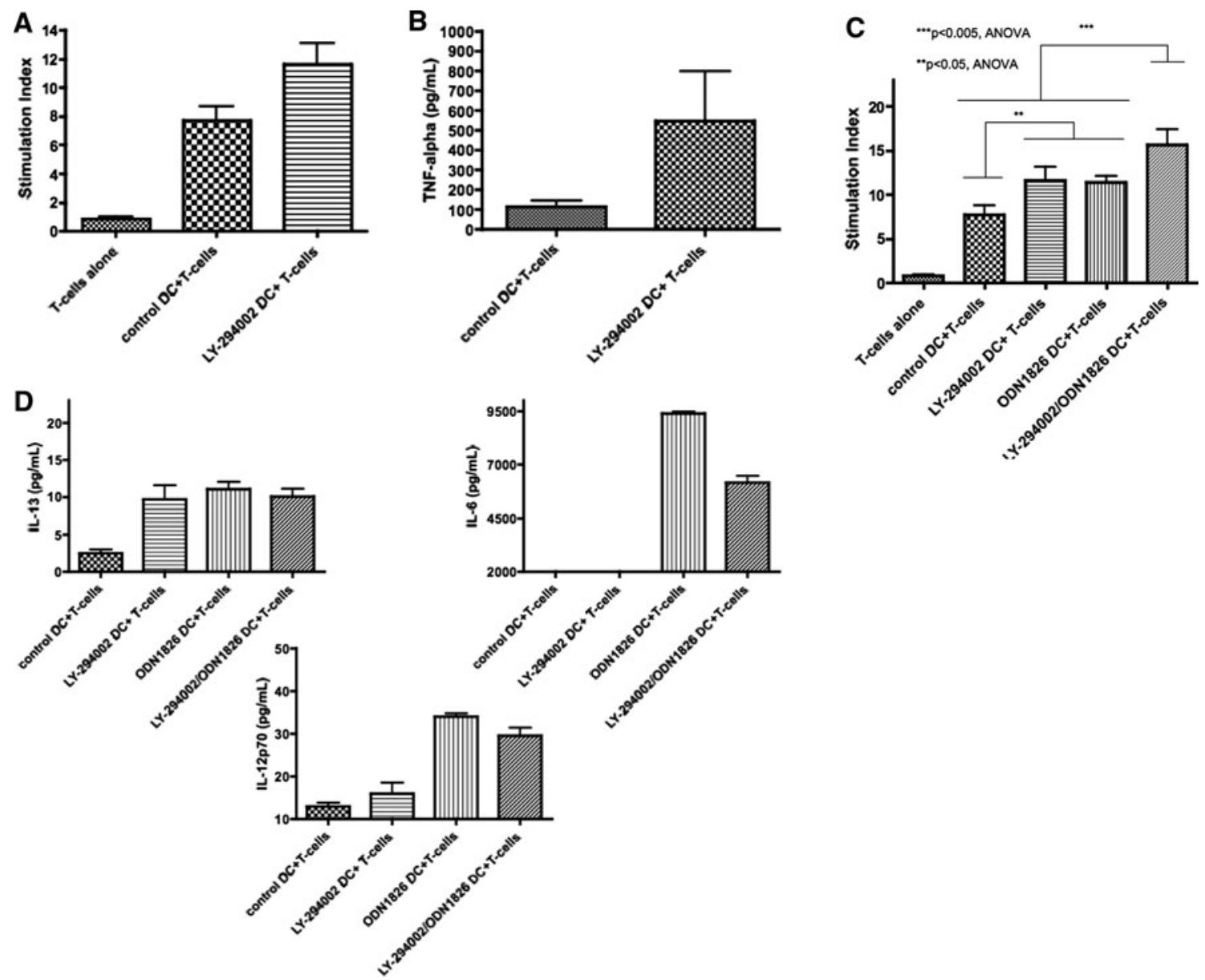

Fig. 9 The addition of LY-294002 with or without ODN 1826 beginning at the time following DC generation results in cells that exhibit immunostimulatory phenotype in vitro. DC were generated by the standard GM-CSF/IL-4 method and on day 6, LY-294002 or ODN 1826 alone, or the combination were added to the generated DC for an overnight incubation. The cells and supernatant were collected and subsequently used in MLR and cytokine profiling. a LY-294002 addition to post-generated DC (i.e. LY-294002 was added at the end of the 6-day DC generation) confers potent immunostimulatory capacity to the cells in allogeneic MLR. An equal number of LY294002 post-generated DC were added to allogeneic splenic T-cells in vitro for a standard five-day MLR. At the end of the 5 day MLR, the cultures were pulsed with BrdU, and after an overnight incubation, the frequency of BrdU+ cells (representing proliferating cell frequency) was measured by FACS. The graph shows the frequency of proliferating cells as a stimulation index $(S I)$. The SI was calculated by dividing the proliferation of T-cells in the different cocultures by background proliferation. Proliferation observed in cultures of T-cells only was considered to be the background level and assigned a value of 1 . The bars represent the means, and the error bars represent the SEM of quintuplicate wells. $P<0.05$ by ANOVA (one-tailed) comparing proliferation of allogeneic T-cells in coculture with LY-294002-post-generated DC. b LY-294002 addition to post-generated DC results in immunostimulatory DC that elicit TNFalpha production by T-cells in MLR in vitro. The supernatants from the allogeneic MLR were collected and screened for the cytokine profile. TNF-alpha was the only consistently detectable cytokine in all experiments. The bars represent the concentration of TNF-alpha as measured by Luminex assay of the MLR supernatants and the error bars the SEM of quintuplicate wells. $P<0.05$ (Student's $t$ test, onetailed). c Co-treatment of post-generated DC with LY-294002 and ODN 1826 results in DC with more potent allostimulatory capacity than post-generated DC treated with only one or the other agent. An equal number of LY-294002/ODN 1826 co-treated post-generated DC were added to allogeneic splenic T-cells in vitro for a standard five-day MLR. For comparison, we repeated the experiment where additional wells included post-generated DC treated only with ODN 1826 or LY-294002. At the end of the 5 day MLR, the cultures were pulsed with BrdU, and after an overnight incubation, the frequency of BrdU+ cells (representing proliferating cell frequency) was measured by FACS. The graph shows the frequency of proliferating cells as a stimulation index $(S I)$. The SI was calculated by dividing the proliferation of T-cells in the different co-cultures by background proliferation. Proliferation observed in cultures of T-cells only was considered to be the background level and assigned a value of 1 . The bars represent the means, and the error bars represent the SEM of quintuplicate wells. Statistically relevant differences in proliferation are indicated with asterisks above the bars (ANOVA, one-tailed). d Co-treatment of post-generated DC with LY-294002 and ODN 1826 yields DC that elicit IL-13, IL-6, and IL-12p70 in vitro in allogeneic MLR, but not TNF-alpha. The supernatants from the allogeneic MLR illustrated in $\mathbf{c}$ were collected and screened for the cytokine profile. Unlike the previous experiment, TNF-alpha was undetectable. The consistently detectable cytokines in all experiments were IL-13, IL-6, and IL-12p70. The bars represent the concentration of the cytokines as measured by Luminex assay of the MLR supernatants and the error bars the SEM of quintuplicate wells 
that the modulation of PI3K could shift the differentiation of monocyte progenitors of DC to either immunosuppressive or immunostimulatory DC. Although PI3K could serve the role of such a regulator during DC generation (and perhaps DC maturation in vivo), PI3K appears to be complementary to other molecular pathways that confer a stimulatory phenotype in differentiated DC. We hypothesise that, although one can generate immunosuppressive and immunostimulatory DC by PI3K modulation during the cell generation/differentiation stage, once DC are fully differentiated from monocytic progenitors, PI3K modulation may play a less important role, especially since impairment of PI3K at the end of the DC generation stage promotes stimulatory DC. These observations are important given the existing clinical applications of DC-based immunostimulatory vaccines and the interest in using autologous DC to treat autoimmunity and to facilitate allotransplantation.

Acknowledgments This work was supported by grants from the RiMed Foundation (to MT and VDC) and the JDRF (to NG). We thank Mr. Bob Lakomy and Ms. Alexis Styche for excellent flow cytometry assistance.

\section{References}

1. Fruman DA, Bismuth G. Fine tuning the immune response with PI3K. Immunol Rev. 2009;228(1):253-72.

2. Ghigo A, Damilano F, Braccini L, Hirsch E. PI3K inhibition in inflammation: toward tailored therapies for specific diseases. Bioessays. 2010;32(3):185-96.

3. Koyasu S. The role of PI3K in immune cells. Nat Immunol. 2003;4(4):313-9.

4. Bhattacharyya S, Sen P, Wallet M, Long B, Baldwin AS Jr, Tisch R. Immunoregulation of dendritic cells by IL-10 is mediated through suppression of the PI3K/Akt pathway and of IkappaB kinase activity. Blood. 2004;104(4):1100-9.

5. Foey AD, Feldmann M, Brennan FM. CD40 ligation induces macrophage IL-10 and TNF-alpha production: differential use of the PI3K and p42/44 MAPK-pathways. Cytokine. 2001;16(4): $131-42$.

6. Frossi B, Rivera J, Hirsch E, Pucillo C. Selective activation of Fyn/ $\mathrm{PI} 3 \mathrm{~K}$ and p38 MAPK regulates IL-4 production in BMMC under nontoxic stress condition. J Immunol. 2007;178(4):2549-55.

7. Fukao T, Tanabe M, Terauchi Y, Ota T, Matsuda S, Asano T, Kadowaki T, Takeuchi T, Koyasu S. PI3K-mediated negative feedback regulation of IL-12 production in DCs. Nat Immunol. 2002;3(9):875-81.

8. Neves BM, Cruz MT, Francisco V, Garcia-Rodriguez C, Silvestre R, Cordeiro-da-Silva A, Dinis AM, Batista MT, Duarte CB, Lopes MC. Differential roles of PI3-Kinase, MAPKs and NF-kappaB on the manipulation of dendritic cell T(h)1/T(h)2 cytokine/chemokine polarizing profile. Mol Immunol. 2009;46(13):2481-92.

9. Okkenhaug K, Vanhaesebroeck B. PI3K in lymphocyte development, differentiation and activation. Nat Rev. 2003;3(4): 317-30.

10. Patel RK, Mohan C. PI3K/AKT signaling and systemic autoimmunity. Immunol Res. 2005;31(1):47-55.

11. Weichhart T, Saemann MD. The PI3K/Akt/mTOR pathway in innate immune cells: emerging therapeutic applications. Ann Rheum Dis. 2008;67(Suppl 3):iii70-4.
12. Harris SJ, Foster JG, Ward SG. PI3K isoforms as drug targets in inflammatory diseases: lessons from pharmacological and genetic strategies. Curr Opin Investig Drugs. 2009;10(11): 1151-62.

13. Caparros E, Munoz P, Sierra-Filardi E, Serrano-Gomez D, PuigKroger A, Rodriguez-Fernandez JL, Mellado M, Sancho J, Zubiaur M, Corbi AL. DC-SIGN ligation on dendritic cells results in ERK and PI3K activation and modulates cytokine production. Blood. 2006;107(10):3950-8.

14. Guiducci C, Ghirelli C, Marloie-Provost MA, Matray T, Coffman RL, Liu YJ, Barrat FJ, Soumelis V. PI3K is critical for the nuclear translocation of IRF-7 and type I IFN production by human plasmacytoid predendritic cells in response to TLR activation. J Exp Med. 2008;205(2):315-22.

15. Karakhanova S, Meisel S, Ring S, Mahnke K, Enk AH. ERK/ p38 MAP-kinases and PI3K are involved in the differential regulation of B7-H1 expression in DC subsets. Eur J Immunol. 2010;40(1):254-66.

16. Xie J, Qian J, Yang J, Wang S, Freeman ME 3rd, Yi Q. Critical roles of Raf/MEK/ERK and PI3K/AKT signaling and inactivation of p38 MAP kinase in the differentiation and survival of monocyte-derived immature dendritic cells. Exp Hematol. 2005;33(5):564-72.

17. Fukao T, Koyasu S. PI3K and negative regulation of TLR signaling. Trends Immunol. 2003;24(7):358-63.

18. An H, Yu Y, Zhang M, Xu H, Qi R, Yan X, Liu S, Wang W, Guo Z, Guo J, et al. Involvement of ERK, p38 and NF-kappaB signal transduction in regulation of TLR2, TLR4 and TLR9 gene expression induced by lipopolysaccharide in mouse dendritic cells. Immunology. 2002;106(1):38-45.

19. Kumagai Y, Takeuchi O, Akira S. TLR9 as a key receptor for the recognition of DNA. Adv Drug Deliv Rev. 2008;60(7): 795-804.

20. Mitchell D, Olive C. Regulation of toll-like receptor-induced chemokine production in murine dendritic cells by mitogenactivated protein kinases. Mol Immunol. 2010;47(11-12):206573.

21. Ruse M, Knaus UG. New players in TLR-mediated innate immunity: PI3K and small Rho GTPases. Immunol Res. 2006; 34(1):33-48.

22. Wohlfert EA, Clark RB. 'Vive la resistance!'-the PI3K-Akt pathway can determine target sensitivity to regulatory $\mathrm{T}$ cell suppression. Trends Immunol. 2007;28(4):154-60.

23. Banchereau J, Steinman RM. Dendritic cells and the control of immunity. Nature. 1998;392(6673):245-52.

24. Lutz MB, Schuler G. Immature, semi-mature and fully mature dendritic cells: which signals induce tolerance or immunity? Trends Immunol. 2002;23(9):445-9.

25. Steinman RM, Hawiger D, Nussenzweig MC. Tolerogenic dendritic cells. Annu Rev Immunol. 2003;21:685-711.

26. Vlad G, Cortesini R, Suciu-Foca N. License to heal: bidirectional interaction of antigen-specific regulatory $\mathrm{T}$ cells and tolerogenic APC. J Immunol. 2005;174(10):5907-14.

27. Nikolic T, Welzen-Coppens JM, Leenen PJ, Drexhage HA, Versnel MA. Plasmacytoid dendritic cells in autoimmune diabetespotential tools for immunotherapy. Immunobiology. 2009; 214(9-10):791-9.

28. Kalinski P. Dendritic cells in immunotherapy of established cancer: roles of signals 1, 2, 3 and 4. Curr Opin Investig Drugs. 2009;10(6):526-35.

29. Melief CJ. Cancer immunotherapy by dendritic cells. Immunity. 2008;29(3):372-83.

30. Nencioni A, Grunebach F, Schmidt SM, Muller MR, Boy D, Patrone F, Ballestrero A, Brossart P. The use of dendritic cells in cancer immunotherapy. Crit Rev Oncol Hematol. 2008;65(3): $191-9$. 
31. Kornbluth RS, Stone GW. Immunostimulatory combinations: designing the next generation of vaccine adjuvants. J Leukoc Biol. 2006;80(5):1084-102.

32. Mahnke K, Schmitt E, Bonifaz L, Enk AH, Jonuleit H. Immature, but not inactive: the tolerogenic function of immature dendritic cells. Immunol Cell Biol. 2002;80(5):477-83.

33. Nouri-Shirazi M, Thomson AW. Dendritic cells as promoters of transplant tolerance. Expert Opin Biol Ther. 2006;6(4):325-39.

34. Bottino R, Lemarchand P, Trucco M, Giannoukakis N. Geneand cell-based therapeutics for type I diabetes mellitus. Gene Ther. 2003;10(10):875-89.

35. Chen D, Sung R, Bromberg JS. Gene therapy in transplantation. Transpl Immunol. 2002;9(2-4):301-14.

36. Giannoukakis N, Trucco M. Gene therapy for type 1 diabetes. Am J Ther. 2005;12(6):512-28.

37. Tarner IH, Slavin AJ, McBride J, Levicnik A, Smith R, Nolan GP, Contag CH, Fathman CG. Treatment of autoimmune disease by adoptive cellular gene therapy. Ann N Y Acad Sci. 2003;998: 512-9.

38. Trucco M, Robbins PD, Thomson AW, Giannoukakis N. Gene therapy strategies to prevent autoimmune disorders. Curr Gene Ther. 2002;2(3):341-54.

39. Chen W. Dendritic cells and $(\mathrm{CD} 4+) \mathrm{CD} 25+\mathrm{T}$ regulatory cells: crosstalk between two professionals in immunity versus tolerance. Front Biosci. 2006;11:1360-70.

40. Hugues S, Boissonnas A, Amigorena S, Fetler L. The dynamics of dendritic cell-T cell interactions in priming and tolerance. Curr Opin Immunol. 2006;18(4):491-5.

41. Beissert S, Schwarz A, Schwarz T. Regulatory T cells. J Invest Dermatol. 2006;126(1):15-24.

42. Enk AH. DCs and cytokines cooperate for the induction of Tregs. Ernst Schering Res Found Workshop. 2006;56:97-106.

43. Huber S, Schramm C. TGF-beta and CD4+ CD25+ regulatory T cells. Front Biosci. 2006;11:1014-23.

44. Lohr J, Knoechel B, Abbas AK. Regulatory $\mathrm{T}$ cells in the periphery. Immunol Rev. 2006;212:149-62.

45. Roncarolo MG, Gregori S, Battaglia M, Bacchetta R, Fleischhauer K, Levings MK. Interleukin-10-secreting type 1 regulatory $\mathrm{T}$ cells in rodents and humans. Immunol Rev. 2006;212: $28-50$.

46. Shevach EM, DiPaolo RA, Andersson J, Zhao DM, Stephens GL, Thornton AM. The lifestyle of naturally occurring CD4+ CD25+ Foxp3+ regulatory T cells. Immunol Rev. 2006;212: 60-73.

47. Tang Q, Bluestone JA. Regulatory T-cell physiology and application to treat autoimmunity. Immunol Rev. 2006;212:217-37.

48. Verhagen J, Blaser K, Akdis CA, Akdis M. Mechanisms of allergen-specific immunotherapy: T-regulatory cells and more. Immunol Allergy Clin North Am. 2006;26(2):207-31.

49. Zhang L, Yi H, Xia XP, Zhao Y. Transforming growth factorbeta: an important role in CD4+ CD25+ regulatory T cells and immune tolerance. Autoimmunity. 2006;39(4):269-76.

50. Munn DH, Sharma MD, Lee JR, Jhaver KG, Johnson TS, Keskin DB, Marshall B, Chandler P, Antonia SJ, Burgess R, et al. Potential regulatory function of human dendritic cells expressing indoleamine 2,3-dioxygenase. Science. 2002;297(5588):1867-70.

51. Mellor AL, Chandler P, Baban B, Hansen AM, Marshall B, Pihkala J, Waldmann H, Cobbold S, Adams E, Munn DH. Specific subsets of murine dendritic cells acquire potent $\mathrm{T}$ cell regulatory functions following CTLA4-mediated induction of indoleamine 2,3 dioxygenase. Int Immunol. 2004;16(10):1391-401.

52. Mellor AL, Munn DH. IDO expression by dendritic cells: tolerance and tryptophan catabolism. Nat Rev Immunol. 2004; 4(10):762-74.
53. Ahuja SS. In vitro generation of functional human and murine dendritic cells. Methods Mol Biol (Clifton, NJ). 2001;156:67-77.

54. Anton D, Dabadghao S, Palucka K, Holm G, Yi Q. Generation of dendritic cells from peripheral blood adherent cells in medium with human serum. Scand J Immunol. 1998;47(2):116-21.

55. Bernhard H, Disis ML, Heimfeld S, Hand S, Gralow JR, Cheever MA. Generation of immunostimulatory dendritic cells from human CD34+ hematopoietic progenitor cells of the bone marrow and peripheral blood. Cancer Res. 1995;55(5):1099-104.

56. Brossart P, Grunebach F, Stuhler G, Reichardt VL, Mohle R, Kanz L, Brugger W. Generation of functional human dendritic cells from adherent peripheral blood monocytes by CD40 ligation in the absence of granulocyte-macrophage colony-stimulating factor. Blood. 1998;92(11):4238-47.

57. Cao H, Verge V, Baron C, Martinache C, Leon A, Scholl S, Gorin NC, Salamero J, Assari S, Bernard J, et al. In vitro generation of dendritic cells from human blood monocytes in experimental conditions compatible for in vivo cell therapy. J Hematother Stem Cell Res. 2000;9(2):183-94.

58. Gluckman JC, Canque B, Chapuis F, Rosenzwajg M. In vitro generation of human dendritic cells and cell therapy. Cytokines Cell Mol Ther. 1997;3(3):187-96.

59. Inaba K, Inaba M, Romani N, Aya H, Deguchi M, Ikehara S, Muramatsu S, Steinman RM. Generation of large numbers of dendritic cells from mouse bone marrow cultures supplemented with granulocyte/macrophage colony-stimulating factor. J Exp Med. 1992;176(6):1693-702.

60. Manca F, Li Pira G, Fenoglio D, Fang SP, Habeshaw A, Knight SC, Dalgleish AG. Dendritic cells are potent antigen-presenting cells for in vitro induction of primary human CD4+ T-cell lines specific for HIV gp120. J Acquir Immune Defic Syndr. 1994; 7(1):15-23.

61. Ratta M, Rondelli D, Fortuna A, Curti A, Fogli M, Fagnoni F, Martinelli G, Terragna C, Tura S, Lemoli RM. Generation and functional characterization of human dendritic cells derived from CD34 cells mobilized into peripheral blood: comparison with bone marrow CD34+ cells. Br J Haematol. 1998;101(4): 756-65.

62. Romani N, Reider D, Heuer M, Ebner S, Kampgen E, Eibl B, Niederwieser D, Schuler G. Generation of mature dendritic cells from human blood. An improved method with special regard to clinical applicability. J Immunol Methods. 1996;196(2):137-51.

63. Arab S, Motamedi M, Khansari N, Moazzeni SM, Gheflati Z, Hadjati J. Dendritic cell maturation with $\mathrm{CpG}$ for tumor immunotherapy. Iran J Immunol. 2006;3(3):99-105.

64. Iparraguirre A, Tobias JW, Hensley SE, Masek KS, Cavanagh LL, Rendl M, Hunter CA, Ertl HC, von Andrian UH, Weninger W. Two distinct activation states of plasmacytoid dendritic cells induced by influenza virus and $\mathrm{CpG} 1826$ oligonucleotide. J Leukoc Biol. 2008;83(3):610-20.

65. Lee KW, Kim DS, Kwon HJ. CG sequence- and phosphorothioate backbone modification-dependent activation of the NFkappaB-responsive gene expression by $\mathrm{CpG}$-oligodeoxynucleotides in human RPMI 8226 B cells. Mol Immunol. 2004; 41(10):955-64.

66. Switaj T, Jalili A, Jakubowska AB, Drela N, Stoksik M, Nowis D, Basak G, Golab J, Wysocki PJ, Mackiewicz A, et al. CpG immunostimulatory oligodeoxynucleotide 1826 enhances antitumor effect of interleukin 12 gene-modified tumor vaccine in a melanoma model in mice. Clin Cancer Res. 2004;10(12 Pt 1): 4165-75.

67. Giannoukakis N, Bonham CA, Qian S, Zhou Z, Peng L, Harnaha J, Li W, Thomson AW, Fung JJ, Robbins PD, et al. Prolongation of cardiac allograft survival using dendritic cells treated with 
NF-kB decoy oligodeoxyribonucleotides. Mol Ther. 2000; 1(5 Pt 1):430-7. (in process citation).

68. Machen J, Harnaha J, Lakomy R, Styche A, Trucco M, Giannoukakis N. Antisense oligonucleotides down-regulating costimulation confer diabetes-preventive properties to nonobese diabetic mouse dendritic cells. J Immunol. 2004;173(7):4331-41.

69. Adorini L, Giarratana N, Penna G. Pharmacological induction of tolerogenic dendritic cells and regulatory T cells. Semin Immu nol. 2004;16(2):127-34.

70. Thomson AW, Robbins PD. Tolerogenic dendritic cells for autoimmune disease and transplantation. Ann Rheum Dis. 2008; 67(Suppl 3):iii90-6.

71. Antignano F, Ibaraki M, Ruschmann J, Jagdeo J, Krystal G. SHIP negatively regulates Flt3L-derived dendritic cell generation and positively regulates MyD88-independent TLR-induced maturation. J Leukoc Biol.

72. Antignano F, Ibaraki M, Kim C, Ruschmann J, Zhang A, Helgason CD, Krystal G. SHIP is required for dendritic cell maturation. J Immunol. 2010;184(6):2805-13.

73. van de Laar L, Buitenhuis M, Wensveen FM, Janssen HL, Coffer PJ, Woltman AM. Human CD34-derived myeloid dendritic cell development requires intact phosphatidylinositol 3-kinase-protein kinase B-mammalian target of rapamycin signaling. J Immunol. 2010;184(12):6600-11.

74. Lo AS, Gorak-Stolinska P, Bachy V, Ibrahim MA, Kemeny DM, Maher J. Modulation of dendritic cell differentiation by colonystimulating factor-1: role of phosphatidylinositol 3'-kinase and delayed caspase activation. J Leukoc Biol. 2007;82(6):1446-54.

75. Kramer PR, Winger V, Reuben J. PI3K limits TNF-alpha production in CD16-activated monocytes. Eur J Immunol. 2009; 39(2):561-70.

76. Fu F, Li Y, Qian S, Lu L, Chambers F, Starzl TE, Fung JJ, Thomson AW. Costimulatory molecule-deficient dendritic cell progenitors (MHC class II+, CD80dim, CD86-) prolong cardiac allograft survival in nonimmunosuppressed recipients. Transplantation. 1996;62(5):659-65.

77. Lu L, Rudert WA, Qian S, McCaslin D, Fu F, Rao AS, Trucco M, Fung JJ, Starzl TE, Thomson AW. Growth of donor-derived dendritic cells from the bone marrow of murine liver allograft recipients in response to granulocyte/macrophage colony-stimulating factor. J Exp Med. 1995;182(2):379-87.

78. Shumilina E, Zahir N, Xuan NT, Lang F. Phosphoinositide 3-kinase dependent regulation of $\mathrm{Kv}$ channels in dendritic cells. Cell Physiol Biochem. 2007;20(6):801-8.

79. Aksoy E, Vanden Berghe W, Detienne S, Amraoui Z, Fitzgerald KA, Haegeman G, Goldman M, Willems F. Inhibition of phosphoinositide 3-kinase enhances TRIF-dependent NF-kappa $\mathrm{B}$ activation and IFN-beta synthesis downstream of toll-like receptor 3 and 4. Eur J Immunol. 2005;35(7):2200-9.

80. Liu E, Law HK, Lau YL. Insulin-like growth factor I promotes maturation and inhibits apoptosis of immature cord blood monocyte-derived dendritic cells through MEK and PI 3-kinase pathways. Pediatr Res. 2003;54(6):919-25.

81. Bhattacharya P, Gopisetty A, Ganesh BB, Sheng JR, Prabhakar BS. GM-CSF-induced, bone-marrow-derived dendritic cells can expand natural Tregs and induce adaptive Tregs by different mechanisms. J Leukoc Biol. 2010.

82. Li H, Zhang GX, Chen Y, Xu H, Fitzgerald DC, Zhao Z, Rostami A. CD11c+ CD11b+ dendritic cells play an important role in intravenous tolerance and the suppression of experimental autoimmune encephalomyelitis. J Immunol. 2008;181(4): 2483-93.

83. Liu Q, Zhang C, Sun A, Zheng Y, Wang L, Cao X. Tumoreducated CD11bhighIalow regulatory dendritic cells suppress $\mathrm{T}$ cell response through arginase I. J Immunol. 2009;182(10): 6207-16.
84. Cobbold SP. T cell tolerance in transplantation: possibilities for therapeutic intervention. Expert Opin Ther Targets. 2002;6(5): 583-99.

85. Hochweller K, Anderton SM. Kinetics of costimulatory molecule expression by $\mathrm{T}$ cells and dendritic cells during the induction of tolerance versus immunity in vivo. Eur J Immunol. 2005;35(4): 1086-96.

86. Chhabra A, Chakraborty NG, Mukherji B. Silencing of endogenous IL-10 in human dendritic cells leads to the generation of an improved CTL response against human melanoma associated antigenic epitope, MART-1 27-35. Clin Immunol. 2008;126(3): 251-9.

87. Gundacker NC, Haudek VJ, Wimmer H, Slany A, Griss J, Bochkov V, Zielinski C, Wagner O, Stockl J, Gerner C. Cytoplasmic proteome and secretome profiles of differently stimulated human dendritic cells. J Proteome Res. 2009;8(6):2799-811.

88. Kwan WH, Boix C, Gougelet N, Fridman WH, Mueller CG. LPS induces rapid IL-10 release by M-CSF-conditioned tolerogenic dendritic cell precursors. J Leukoc Biol. 2007;82(1): 133-41.

89. Mnasria K, Lagaraine C, Manaa J, Lebranchu Y, Oueslati R. Anti CD25 treatment of human dendritic cells modulates both their cytokine synthesis profiles and their capacity to activate allogeneic CD4 T cells: a potential tolerogenic effect. Int Immunopharmacol. 2008;8(3):414-22.

90. Ureta G, Osorio F, Morales J, Rosemblatt M, Bono MR, Fierro JA. Generation of dendritic cells with regulatory properties. Transpl Proc. 2007;39(3):633-7.

91. Crane IJ, Forrester JV. Th1 and Th2 lymphocytes in autoimmune disease. Crit Rev Immunol. 2005;25(2):75-102.

92. Kutlu A, Bozkurt B, Ciftci F, Bozkanat E. Th1-Th2 interaction: is more complex than a see-saw? Scand J Immunol. 2007;65(4): 393-5.

93. Moss RB, Moll T, El-Kalay M, Kohne C, Soo Hoo W, Encinas J, Carlo DJ. Th1/Th2 cells in inflammatory disease states: therapeutic implications. Exp Opin Biol Ther. 2004;4(12):1887-96.

94. Pirenne J, Kitade H, Kawai M, Koshiba T, Van Damme B, Mathieu C, Waer M. Regulatory cells, TH1/TH2 unbalance, and antibody-induced chronic rejection in operational tolerance induced by donor-specific blood transfusion. Transplantation. 2005;79(3 Suppl):S25-7.

95. Utsugi M, Dobashi K, Ono A, Ishizuka T, Matsuzaki S, Hisada T, Shimizu Y, Kawata T, Aoki H, Kamide Y, et al. PI3K p110beta positively regulates lipopolysaccharide-induced IL-12 production in human macrophages and dendritic cells and JNK1 plays a novel role. J Immunol. 2009;182(9):5225-31.

96. Kamda JD, Singer SM. Phosphoinositide 3-kinase-dependent inhibition of dendritic cell interleukin-12 production by Giardia lamblia. Infect Immun. 2009;77(2):685-93.

97. Ohtani M, Nagai S, Kondo S, Mizuno S, Nakamura K, Tanabe M, Takeuchi T, Matsuda S, Koyasu S. Mammalian target of rapamycin and glycogen synthase kinase 3 differentially regulate lipopolysaccharide-induced interleukin-12 production in dendritic cells. Blood. 2008;112(3):635-43.

98. Agrawal A, Agrawal S, Cao JN, Su H, Osann K, Gupta S. Altered innate immune functioning of dendritic cells in elderly humans: a role of phosphoinositide 3-kinase-signaling pathway. J Immunol. 2007;178(11):6912-22.

99. Vollmer J. Progress in drug development of immunostimulatory CpG oligodeoxynucleotide ligands for TLR9. Exp Opin Biol Ther. 2005;5(5):673-82.

100. Martin M, Rehani K, Jope RS, Michalek SM. Toll-like receptormediated cytokine production is differentially regulated by glycogen synthase kinase 3. Nat Immunol. 2005;6(8):777-84.

101. Pan K, Wang H, Liu WL, Zhang HK, Zhou J, Li JJ, Weng DS, Huang W, Sun JC, Liang XT, et al. The pivotal role of p38 and 
NF-kappaB signal pathways in the maturation of human monocyte-derived dendritic cells stimulated by streptococcal agent OK-432. Immunobiology. 2009;214(5):350-8.

102. Trompezinski S, Migdal C, Tailhardat M, Le Varlet B, Courtellemont P, Haftek M, Serres M. Characterization of early events involved in human dendritic cell maturation induced by sensitizers: cross talk between MAPK signalling pathways. Toxicol Appl Pharmacol. 2008;230(3):397-406.

103. Luft T, Rodionova E, Maraskovsky E, Kirsch M, Hess M, Buchholtz C, Goerner M, Schnurr M, Skoda R, Ho AD. Adaptive functional differentiation of dendritic cells: integrating the network of extra- and intracellular signals. Blood. 2006;107(12): 4763-9.

104. Nakahara T, Moroi Y, Uchi H, Furue M. Differential role of MAPK signaling in human dendritic cell maturation and Th1/ Th2 engagement. J Dermatol Sci. 2006;42(1):1-11.

105. Hua F, Henstock PV, Tang B. ERK activation by GM-CSF reduces effectiveness of p38 inhibitor on inhibiting TNFalpha release. Int Immunopharmacol. 2010;10(7):730-7.

106. Lendemans S, Rani M, Selbach C, Kreuzfelder E, Schade FU, Flohe S. GM-CSF priming of human monocytes is dependent on ERK1/2 activation. J Endotoxin Res. 2006;12(1):10-20.

107. Nagafuchi S, Katsuta H, Ohno Y, Inoue Y, Shimoda K, Kogawa K, Ikeda Y, Koyanagi-Katsuta R, Yamasaki S, Tominaga H, et al. Mitogen-activated protein kinase pathway controls autoimmune regulator (AIRE) gene expression in granulo-monocyte colony stimulating factor (GM-CSF)-stimulated myelomonocytic leukemia OTC-4 cells. Immunol Lett. 2005;99(1):130-5.

108. Nagayama H, Sato K, Kawasaki H, Enomoto M, Morimoto C, Tadokoro K, Juji T, Asano S, Takahashi TA. IL-12 responsiveness and expression of IL-12 receptor in human peripheral blood monocyte-derived dendritic cells. J Immunol. 2000;165(1): 59-66.

109. Koski GK, Lyakh LA, Cohen PA, Rice NR. CD14+ monocytes as dendritic cell precursors: diverse maturation-inducing pathways lead to common activation of NF-kappab/RelB. Crit Rev Immunol. 2001;21(1-3):179-89.

110. Stepnik M, Arkusz J. Molecular events associated with dendritic cells activation by contact sensitizers. Int J Occup Med Environ Health. 2003;16(3):191-9.

111. Rehani K, Wang H, Garcia CA, Kinane DF, Martin M. Toll-like receptor-mediated production of IL-1Ra is negatively regulated by GSK3 via the MAPK ERK1/2. J Immunol. 2009;182(1): 547-53.

112. Hu X, Paik PK, Chen J, Yarilina A, Kockeritz L, Lu TT, Woodgett JR, Ivashkiv LB. IFN-gamma suppresses IL-10 production and synergizes with TLR2 by regulating GSK3 and CREB/AP-1 proteins. Immunity. 2006;24(5):563-74.

113. Spinnler K, Mezger M, Steffens M, Sennefelder H, Kurzai O, Einsele H, Loeffler J. Role of glycogen synthase kinase 3 (GSK3 ) in innate immune response of human immature dendritic cells to Aspergillus fumigatus. Med Mycol. 2010;48(4):589-97.

114. Lin CF, Tsai CC, Huang WC, Wang CY, Tseng HC, Wang Y, Kai JI, Wang SW, Cheng YL. IFN-gamma synergizes with LPS to induce nitric oxide biosynthesis through glycogen synthase kinase-3-inhibited IL-10. J Cell Biochem. 2008;105(3):746-55.

115. Rodionova E, Conzelmann M, Maraskovsky E, Hess M, Kirsch M, Giese T, Ho AD, Zoller M, Dreger P, Luft T. GSK-3 mediates differentiation and activation of proinflammatory dendritic cells. Blood. 2007;109(4):1584-92.

116. Duperrier K, Velten FW, Bohlender J, Demory A, Metharom P, Goerdt S. Immunosuppressive agents mediate reduced allostimulatory properties of myeloid-derived dendritic cells despite induction of divergent molecular phenotypes. Mol Immunol. 2005;42(12):1531-40.
117. Lu L, Lee WC, Takayama T, Qian S, Gambotto A, Robbins PD, Thomson AW. Genetic engineering of dendritic cells to express immunosuppressive molecules (viral IL-10, TGF-beta, and CTLA4Ig). J Leukoc Biol. 1999;66(2):293-6.

118. Wada A. GSK-3 inhibitors and insulin receptor signaling in health, disease, and therapeutics. Front Biosci. 2009;14:1558-70.

119. MacAulay K, Woodgett JR. Targeting glycogen synthase kinase-3 (GSK-3) in the treatment of Type 2 diabetes. Expert Opin Ther Targets. 2008;12(10):1265-74.

120. Mucci I, Legitimo A, Compagnino M, Consolini R, Migliaccio $\mathrm{P}$, Metelli MR, Scatena F. The methodological approach for the generation of human dendritic cells from monocytes affects the maturation state of the resultant dendritic cells. Biologicals. 2009;37(5):288-96.

121. Elkord E, Williams PE, Kynaston H, Rowbottom AW. Human monocyte isolation methods influence cytokine production from in vitro generated dendritic cells. Immunology. 2005;114(2): 204-12.

122. Colic M, Mojsilovic S, Pavlovic B, Vucicevic D, Majstorovic I, Bufan B, Stojic-Vukanic Z, Vasilijic S, Vucevic D, Gasic S, et al. Comparison of two different protocols for the induction of maturation of human dendritic cells in vitro. Vojnosanit Pregl. 2004;61(5):471-8.

123. Franke TF. PI3K/Akt: getting it right matters. Oncogene. 2008; 27(50):6473-88.

124. Franke TF, Hornik CP, Segev L, Shostak GA, Sugimoto C. PI3K/Akt and apoptosis: size matters. Oncogene. 2003;22(56): 8983-98.

125. McCubrey JA, Steelman LS, Abrams SL, Bertrand FE, Ludwig DE, Basecke J, Libra M, Stivala F, Milella M, Tafuri A, et al. Targeting survival cascades induced by activation of Ras/Raf/ MEK/ERK, PI3K/PTEN/Akt/mTOR and Jak/STAT pathways for effective leukemia therapy. Leukemia. 2008;22(4):708-22.

126. Cho DC, Cohen MB, Panka DJ, Collins M, Ghebremichael M, Atkins MB, Signoretti S, Mier JW. The efficacy of the novel dual PI3-kinase/mTOR inhibitor NVP-BEZ235 compared with rapamycin in renal cell carcinoma. Clin Cancer Res. 2010; 16(14):3628-38.

127. Fujiwara M, Izuishi K, Sano T, Hossain MA, Kimura S, Masaki T, Suzuki Y. Modulating effect of the PI3-kinase inhibitor LY294002 on cisplatin in human pancreatic cancer cells. J Exp Clin Cancer Res. 2008;27:76.

128. Burchert A, Wang Y, Cai D, von Bubnoff N, Paschka P, Muller-Brusselbach S, Ottmann OG, Duyster J, Hochhaus A, Neubauer A. Compensatory PI3-kinase/Akt/mTor activation regulates imatinib resistance development. Leukemia. 2005;19(10): 1774-82.

129. Aikawa R, Nawano M, Gu Y, Katagiri H, Asano T, Zhu W, Nagai R, Komuro I. Insulin prevents cardiomyocytes from oxidative stress-induced apoptosis through activation of PI3 kinase/ Akt. Circulation. 2000;102(23):2873-9.

130. Rane MJ, Coxon PY, Powell DW, Webster R, Klein JB, Pierce W, Ping P, McLeish KR. p38 Kinase-dependent MAPKAPK-2 activation functions as 3-phosphoinositide-dependent kinase-2 for Akt in human neutrophils. J Biol Chem. 2001;276(5): 3517-23.

131. Berra E, Diaz-Meco MT, Moscat J. The activation of p38 and apoptosis by the inhibition of Erk is antagonized by the phosphoinositide 3-kinase/Akt pathway. J Biol Chem. 1998;273(17): 10792-7.

132. Gratton JP, Morales-Ruiz M, Kureishi Y, Fulton D, Walsh K, Sessa WC. Akt down-regulation of $\mathrm{p} 38$ signaling provides a novel mechanism of vascular endothelial growth factor-mediated cytoprotection in endothelial cells. J Biol Chem. 2001; 276(32):30359-65. 
133. Ammon C, Mondal K, Andreesen R, Krause SW. Differential expression of the transcription factor NF-kappaB during human mononuclear phagocyte differentiation to macrophages and dendritic cells. Biochem Biophys Res Commun. 2000;268(1): 99-105.

134. Rescigno M, Martino M, Sutherland CL, Gold MR, RicciardiCastagnoli P. Dendritic cell survival and maturation are regulated by different signaling pathways. J Exp Med. 1998;188(11): 2175-80.

135. Jones RG, Saibil SD, Pun JM, Elford AR, Bonnard M, Pellegrini M, Arya S, Parsons ME, Krawczyk CM, Gerondakis S, et al. NF-kappaB couples protein kinase B/Akt signaling to distinct survival pathways and the regulation of lymphocyte homeostasis in vivo. J Immunol. 2005;175(6):3790-9.

136. Ohashi PS, Woodgett JR. Modulating autoimmunity: pick your PI3 kinase. Nat Med. 2005;11(9):924-5.
137. Woodgett JR, Ohashi PS. GSK3: an in-toll-erant protein kinase? Nat Immunol. 2005;6(8):751-2.

138. Dil N, Marshall AJ. Role of phosphoinositide 3-kinase p110 delta in TLR4- and TLR9-mediated B cell cytokine production and differentiation. Mol Immunol. 2009;46(10):1970-8.

139. Hoarau C, Gerard B, Lescanne E, Henry D, Francois S, Lacapere JJ, El Benna J, Dang PM, Grandchamp B, Lebranchu Y, et al. TLR9 activation induces normal neutrophil responses in a child with IRAK-4 deficiency: involvement of the direct PI3K pathway. J Immunol. 2007;179(7):4754-65.

140. Sester DP, Brion K, Trieu A, Goodridge HS, Roberts TL, Dunn J, Hume DA, Stacey KJ, Sweet MJ. CpG DNA activates survival in murine macrophages through TLR9 and the phosphatidylinositol 3-kinase-Akt pathway. J Immunol. 2006;177(7):4473-80. 